Portland State University

PDXScholar

Summer 8-14-2019

\title{
Does X Mark the Applicant? Assessing Reactions to Gender Non-Binary Job Seekers
}

Kelly Mason Hamilton

Portland State University

Follow this and additional works at: https://pdxscholar.library.pdx.edu/open_access_etds

Part of the Gender and Sexuality Commons, and the Psychology Commons Let us know how access to this document benefits you.

\section{Recommended Citation}

Hamilton, Kelly Mason, "Does X Mark the Applicant? Assessing Reactions to Gender Non-Binary Job Seekers" (2019). Dissertations and Theses. Paper 5266.

https://doi.org/10.15760/etd.7139

This Thesis is brought to you for free and open access. It has been accepted for inclusion in Dissertations and Theses by an authorized administrator of PDXScholar. Please contact us if we can make this document more accessible: pdxscholar@pdx.edu. 
Does X Mark the Applicant?

Assessing Reactions to Gender Non-Binary Job Seekers

by

Kelly Mason Hamilton

A thesis submitted in partial fulfillment of the requirements for the degree of

Master of Science

in

Psychology

Thesis Committee:

Larry R. Martinez, Chair

Jennifer K. Dimoff

Tessa L. Dover

Portland State University

2019 
(C) 2019 Kelly Mason Hamilton 


\begin{abstract}
The number of individuals who identify as a non-binary gender has almost tripled over the last 10 years. This growing population, and the legal protection against sex discrimination afforded to them under Title VII, puts a responsibility on employers to better understand their experiences in the workplace. The purpose of the current study was to examine how disclosing a non-binary gender identity when applying for jobs influenced hiring outcomes. Specifically, my study assessed (a) hiring managers' beliefs about non-binary gender identities, (b) how those beliefs impacted hiring managers' perceived ability to provide social support to prospective applicants, and (c) how those beliefs and perceptions subsequently impacted their evaluations of and hiring intentions toward applicants who did or did not disclose a non-binary gender identity. I randomly assigned participants to one of four conditions ([self-disclosure: yes vs. no] x [other disclosure: yes vs. no]) and asked them to evaluate applicants via an online experiment. Although results did not reveal a significant effect of disclosure on hiring and support outcomes or a significant indirect effect of disclosure on hiring outcomes through support, there was a conditional indirect effect for one method of disclosure. I discuss theoretical and practical implications, study limitations, and avenues for future research.
\end{abstract}




\section{Table of Contents}

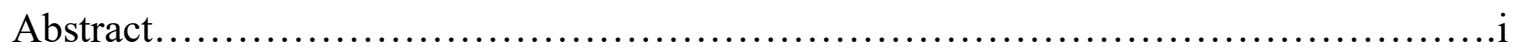

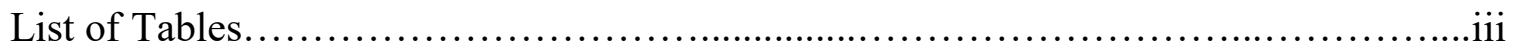

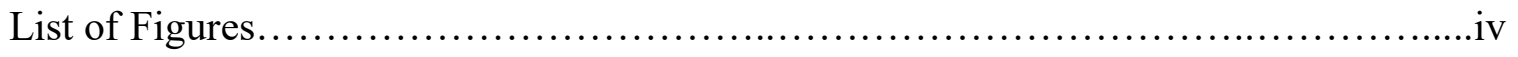

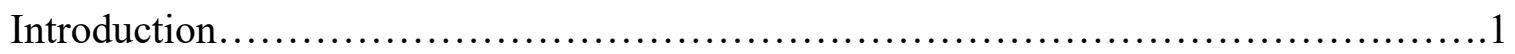

Non-Binary Gender Identities and Expression.......................................5

Hypothesis Development..................................................8

Disclosure in Selection Contexts........................................ 8

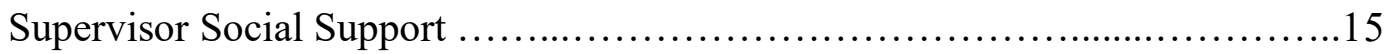

Gender Identity Instability Beliefs...................................... 19

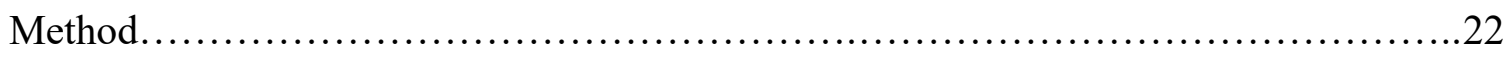

Participants..................................................... 22

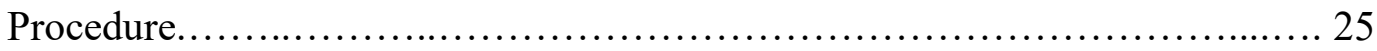

Materials.........................................................27

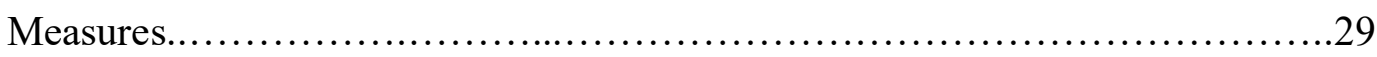

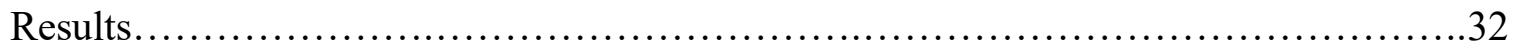

Hypothesis Testing.................................................. 33

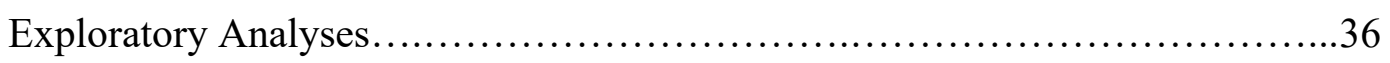

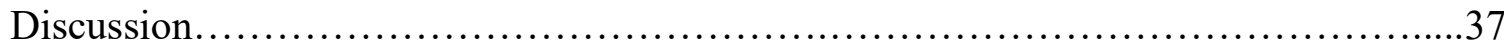

Theoretical and Practical Implications..................................41

Limitations and Future Directions.....................................45

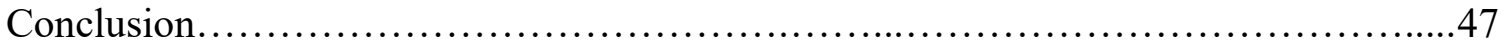

Tables.................................................................. 48

Figures............................................................... 52

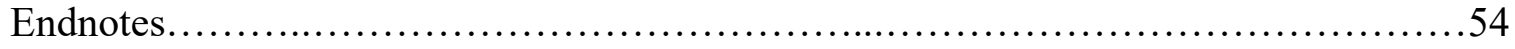

References............................................................55

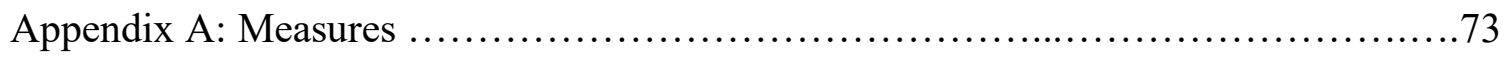

Appendix B: Pilot Study .................................................... 78

Appendix C: Instructions and Stimuli.......................................... 84 


\section{List of Tables}

Table 1: Inter-item Correlations and Reliabilities for All Study Variables...............48

Table 2: Means and Standard Deviations for All Study Variables, by Disclosure

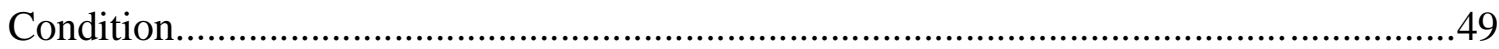

Table 3: Bootstrapped (10,000 Samples) Mediation Analyses for the Effect of Disclosure Condition on Hireability through Perceived Ability to Provide Support...................50

Table 4: Bootstrapped $(10,000)$ Conditional Indirect Effects Analyses for the Effect of Non-binary Gender Instability Beliefs on the Influence of Disclosure Condition on

Hireability Outcomes through Perceived Ability to Provide Support......................51 


\section{List of Figures}

Figure 1: Hypothesized relationships between variables of interest $\ldots \ldots \ldots \ldots \ldots \ldots \ldots \ldots . \ldots 52$

Figure 2: Moderated Mediation Results........................................53 


\section{Introduction}

In June, 2017, Jamie Shupe of Portland, Oregon became the first person in the U.S. to be legally recognized as "gender non-binary" (Mele, 2017) — that is, not exclusively male or female. Within months, Washington State, California, and Washington, D.C. followed suit, and additional states have already adopted similar policies and legislation (Sanders, 2017). This new designation (“Gender X”) benefits non-binary individuals, who make up a subset of the transgender population. Because there is limited research on individuals who identify as non-binary and most research does not include non-binary as a gender response category, the number of non-binary people living in the U.S. is uncertain (Webb, Matsuno, Budge, Krishnan, \& Balsam, 2015). In 2016, the National Center for Transgender Equality issued a report suggesting that of the estimated 1.4 million transgender adults in the U.S., 25-35\% identify as nonbinary, a number that has almost tripled since 2008 (Flores, Herman, Gates, \& Brown, 2016; James, Herman, Rankin, Keisling, Mottet, \& Anafi, 2016). This growing population, and the legal protection against sex discrimination afforded to them under Title VII, puts a responsibility on employers to better understand their experiences in the workplace.

Although awareness of the issues faced by transgender individuals has steadily grown over the last decade, anti-transgender workplace discrimination remains highly prevalent. More than $30 \%$ of transgender and gender non-binary individuals have reported being fired, denied a promotion, not being hired for a job, or experiencing some other form of mistreatment at work (James et al., 2016). The unemployment rate for 
transgender individuals in the U.S. is also twice the national rate (James et al., 2016). Such discrimination has been shown to impact work outcomes including increased turnover and emotional exhaustion, and decreased job satisfaction (Brown, Dashjian, Acosta, Mueller, Kizer, \& Trangsrud, 2012; Budge, Tebbe, \& Howard, 2010; Levitt \& Ippolito, 2014; Schilt \& Connell, 2007; Thoroughgood, Sawyer, \& Webster, 2017). Although it is likely that gender non-binary individuals face similar forms of prejudice and discrimination as the larger transgender population (defined here as people who identify as the opposite gender from the sex they were assigned at birth), it is likely they also experience unique challenges related to how they manage their identities at work (e.g., disclosure). One important distinction is that although transgender individuals may disclose to coworkers a transition across the gender binary (from male to female or from female to male), non-binary individuals must disclose a gender that is outside or in the middle of the gender binary. This disclosure may lead to very different reactions from coworkers, supervisors, and potential employers than those received by transgender individuals who have adopted and possibly assimilated into traditional gender roles and norms (James et al., 2016; Schilt \& Connell, 2007). I propose that negative reactions coworkers often have to gender non-binary individuals stems not from a gender role violation (of the sex they were assigned at birth), but instead from a gender invalidation process through which interaction partners (e.g., coworkers) do not consider gender nonbinary to be a real identity, leading to other forms of discrimination and mistreatment. It is therefore likely they will face different forms of discrimination throughout the employment process based on gender role stereotypes than transgender people who 
identify as men or women (Heilman \& Eagly, 2008). This likely impacts identity management strategies non-binary individuals use upon entering an organization, during which time many must disclose in order to be referred to with their correct pronouns (e.g., the commonly used singular "they"). These different strategies will also likely elicit different reactions from hiring managers and may affect their perceived ability to provide adequate support to such employees and hireability.

The purpose of the current study was to examine how disclosing a non-binary gender identity when applying for jobs influences hiring outcomes. Specifically, my study assesses (a) hiring managers' beliefs about non-binary gender identities, (b) how those beliefs impact hiring managers' perceived ability to provide social support to prospective applicants, and (c) how those beliefs and perceptions subsequently impact their evaluations of and hiring intentions toward applicants who disclose a non-binary gender identity. By focusing exclusively on non-binary individuals, this study extends the existing research on transgender individuals at work, which has previously treated them as a monolithic group (Martinez et al., 2017; Thoroughgood et al., 2017; Budge et al., 2010). In the sections that follow, I first provide background information on non-binary gender identities and disclosure in selection contexts. Second, I introduce stigma theory and relevant gender and identity theories, and discuss impression management strategies non-binary individuals may use in selection contexts. Third, I embed those in a social support framework. Fourth, I posit that a perceived inability to provide social support to prospective job candidates may lead to lower applicant evaluations and that a disbelief in non-binary identities increases that effect. Fifth, I outline the methodology to evaluate 
these relationships and provide the results from analyses. Finally, I discuss implications of the research, as well as its theoretical and practical contributions. 


\section{Non-Binary Gender Identities and Expression}

Over the last 50 years, the transgender community has shifted dramatically in demographics and terminology used to describe identities (Fogarty \& Zheng, 2018). I will use terminology presented by the National Center for Transgender Equality and other community-driven resources (NCTE, 2018; Fogarty \& Zheng, 2018). Transgender is an umbrella term referring to individuals whose gender identities are different from the gender they were thought to be at birth; in other words, their sense of self related to gender does not correspond with their birth sex. Gender identity refers to a person's innate, deeply felt psychological identification as male or female. Most people are cisgender, meaning they have gender identities that align with their gender assignment, but there are an estimated 1.4 million transgender people in the U.S. who do not (NCTE, 2018). The majority of transgender individuals identify with the gender opposite from their birth sex, and many transition to that gender internally (focused on internal changes to gender identity), socially (focused on changing outside perceptions of gender identity), and/or physically (focused on changes to physiology or gender expression; Fogarty \& Zheng, 2018). In this way, the majority of people who identify as transgender can be seen as located along a gender binary and moving from one end of the binary to the other.

Non-binary individuals, on the other hand, instead identify in between or outside the binary altogether (Fogarty \& Zheng, 2018). Some non-binary individuals identify as genderqueer, a word that describes the refusal of all categories of gender identity (Love, 2014) and functions as "both an umbrella identity encompassing non-binary identities and as a stand-alone identity" (Fogarty \& Zheng, 2018). Some non-binary individuals 
may also identify as genderfluid in that they experience their gender as being in flux or varying over time, sometimes daily or hourly (Fogarty \& Zheng, 2018). This fluctuation in identities can often contribute to the perception by others that one's past identities (and therefore current and/or future identities) were "just a phase.” Whereas gender identity refers to one's internal sense of one's own gender along two spectra related to feeling male or female, gender expression is one's outward expression of gender along two spectra related to expressing masculine or feminine characteristics (Hamilton, Park, Carsey, \& Martinez, 2019). Non-binary individuals may employ several tangible strategies to align their outward gender expressions with their identities, including adopting gender neutral names and pronouns (e.g., the singular "they" rather than "he" or "she") and changing their physical appearance to align with their individual sense of masculinity, femininity, or lack of either. Indeed, many non-binary people intentionally create ambiguity through their gender expression and express themselves in a way that defies a single sex assignment over time (Fogarty, 2018; Richards et al., 2016).

According to a national survey of transgender and non-binary individuals, $84 \%$ of respondents reported using pronouns that were different from those associated with the sex on their original birth certificate and asking others to use those pronouns when referring to them (James et al., 2016). Despite these attempts to receive verification from others, more than two-thirds of non-binary respondents reported that other people typically perceive them to be the gender they were assigned at birth, which results in misgendering (James et al., 2016). This lack of clarity related to non-binary identities 
highlights the need for non-binary individuals to disclose their identities to others to achieve authentic working relationships. 


\section{Hypothesis Development}

\section{Disclosure in Selection Contexts}

Identity management is a decision-making process that involves making choices about whether, when, and how to reveal one's identity (disclosure) to others and requires a cost-benefit analysis on the part of the stigmatized individual because it can have important consequences for job outcomes (Jones \& King, 2013; Ragins, 2008). A primary reason many individuals with stigmatized identities choose to disclose is to achieve a sense of authenticity and relatedness with coworkers (Jones \& King, 2013; Swann, 1987). This is explained by self-verification theory, which holds that individuals are motivated to have others see them as they see themselves and that they have a basic need to affirm their identities even if their identities are devalued (Swann, 1983). Thus, disclosure serves a broader need to achieve authenticity in expression and selfverification. It is likely that non-binary individuals would want to disclose their gender identities to prospective employers for many reasons. Doing so would allow them to establish authentic relationships early on, gauge the prospective employer's reactions, and assess whether the workplace is inclusive before deciding whether they will accept a future job offer. Disclosing in job application materials (e.g., resume or cover letter) would also allow them to communicate what names and pronouns they use prior to a face-to-face interview and reduce potential awkwardness in those in-person interactions.

To help provide empirical context for this study and develop my hypotheses, I interviewed 15 people who identify as non-binary as part of a separate project (Hamilton \& Martinez, 2019). The interviews revealed several themes, the most relevant for this 
study being that although formal and interpersonal discrimination are common, the majority (12 out of 15 participants) reported they would likely disclose their non-binary gender identities during the application or interview process out of a need for authenticity and/or to preempt future job discrimination. Specifically, a majority reported they would likely disclose on application materials (e.g., a resume or cover letter; 8 out of 15) or during interviews (12 out of 15) based on their need to be supported early on by their future employers. In my interviews, virtually all participants reported that they would like to be "out" on their first day of employment in their next job. Other data related to disclosure of non-binary identities in workplace contexts shows that only a minority (35\%) of respondents reported concealing their non-binary identity out of a fear of losing their jobs or not getting a job (James et al., 2016).

Empirical research on transgender employees indicates that they often feel the need to disclose their identities at work for similar reasons and that such disclosures can have positive outcomes (Jones \& King, 2013; Martinez et al., 2017). First, they may need to make certain identity-related requests or access specific resources, such as asking coworkers to use the appropriate pronoun when referring to them, or to gain access to a bathroom that aligns with their gender identity (James et al., 2016). Transgender employees also disclose their identities to achieve a greater sense of authenticity (Jones \& King, 2013; Martinez et al., 2017). Indeed, research on transgender individuals has found an increased sense of authenticity following disclosure such that the extent to which coworkers perceived them in a way that aligned with their gender identity led to more 
positive job outcomes such as increased person-organization fit and job satisfaction, and lower levels of perceived discrimination (Martinez et al., 2017).

Despite these positive outcomes on an intrapersonal level, disclosing a stigmatized identity may lead to increased interpersonal discrimination for multiple reasons (Clair et al., 2005; Jones, Farina, Hastorf, Miller, \& Scott, 1984). First, stigmas elicit prejudicial reactions from others when they are viewed as having certain characteristics, such as being controllable, disruptive, threatening, or changing over time (Jones et al., 1984). Stigmas are individual attributes (i.e., "marks") that are seen as personal flaws within a social context (Goffman, 1963). People with stigmatized identities may be perceived as having deviant, repulsive, or otherwise undesirable characteristics that reflect either their character, group membership, or physical body (Goffman, 1963). As a social process, stigmatization involves both targets and perceivers and often leads to discrimination against stigmatized groups (Dovidio, Major, \& Crocker, 2000; Heatherton, Kleck, Hebl, \& Hull, 2000). As a result, stigmas may directly shape the identities and influence the behaviors of stigmatized individuals (Dovidio et al., 2000). Second, disclosing a non-binary identity may evoke negative reactions from others due to strongly held gender role beliefs. Social role theory suggests that because people hold beliefs about men and women based on roles they have performed throughout history, they would react negatively toward people who possess attributes incongruent with those associated with the role of their birth sex (Eagly, 1987; Heilman \& Eagly, 2008). 
Empirical research has indeed found that disclosing a transgender identity is associated with an increase in perceived discrimination, hostility, and isolation from coworkers (Budge et al., 2010). As previously mentioned, research on the broader transgender community has found that at least $30 \%$ of transgender people have experienced discrimination or harassment-a more hostile form of gender-based discrimination-based on their gender identities (James et al., 2016). Forms of discrimination and harassment include being fired or not hired based on one's gender identity, coworkers' refusal to use the correct name and pronouns, being physically threatened, and being forced to follow a dress code that did not align with one's gender identity. This level of discrimination and harassment is associated with stress due to anticipated discrimination and the awareness that there is a lack of laws protecting transgender individuals from discrimination (Chung, 2001; Flojo, 2006).

Based on these theoretical reasons and empirical findings, I predict that nonbinary individuals whose gender identity is disclosed on a job application will be rated with lower applicant evaluations by hiring managers than (presumably cisgender) applicants who do not disclose a gender on their application materials.

Hypothesis 1. Job applications that include the disclosure of a gender non-binary identity will receive lower perceptions of hireability than job applications that do not include a gender identity disclosure.

I also anticipate that the method of disclosure will have an impact on job outcomes. Specifically, I expect that prospective employers will rate non-binary applicants differently as a function of who discloses the identity-the applicant, a letter of 
recommendation writer, or both. Research indicates people utilize various selfpresentation tactics when applying for jobs (Waung, McAuslan, DiMambro, \& Miegoc, 2017). Indeed, job applicants have been found to attempt to convey positive images and to attempt to influence hiring decisions (e.g., Bolino, Kacmar, Turnley, \& Gilstrap, 2008). Such tactics represent attempts to control the image that one projects to others, a concept known as impression management (Jones \& Pittman, 1982; Schlenker, 1980). Jones \& Pittman (1982) developed a taxonomy of five self-presentation strategies, which include self-promotion (e.g., emphasizing competence by highlighting exceptional aptitudes or past experiences), ingratiation (e.g., increasing likeability by being extra polite, giving a gift, flattery, favor doing, or opinion conformity), exemplification (e.g., securing respect and admiration by demonstrating integrity and moral worthiness); supplication (e.g., soliciting help from others by projecting dependence, weakness, and disadvantage); and intimidation (e.g., motivating compliance in others by convincing them that they are dangerous). Self-promotion tactics aimed at increasing perceptions of competence and ingratiation tactics aimed at increasing likeability are the most relevant to the selection context (Ellis, West, Ryan, \& DeShon, 2002; Jones \& Pittman, 1982). In particular, resumes and cover letters are the most obvious materials in which an applicant can attempt to form a good impression among hiring managers before meeting (Waung et al., 2017), as these are widely used by organizations to screen applications and are thus an important part of the hiring process (Burns, Christiansen, Morris, Periard, \& Coaster, 2014). 
Some applicants may choose to ask other people (e.g., past employers or other professional references) to disclose their non-binary gender identities on their behalf as a way of providing accurate gender identity-related information (in an attempt to achieve authenticity) in a diplomatic way (avoiding potential backlash associated with selfdisclosure). Letters of recommendation are commonly used as a selection tool and have a lot of influence in the decision-making process (Cascio \& Aguinis, 2004). Indeed, they have been identified as one of the most important criterion used to screen and evaluate job applicants in a number of job contexts (Johnson et al., 1998, McCarthy \& Goffin, 2001; Landrum, Jeglum, \& Cashin, 1994; Lopez, Oehlert, \& Moberly, 1996; Sheehan, McDevitt, \& Ross, 1998). It is common practice for job applicants to ask former supervisors or colleagues to write letters of recommendation highlighting the applicant's professional strengths and qualifications, past performance, personal character, and anecdotal information that may be useful to the applicant's prospective future employer (Brem, Lampman, \& Johnson, 1995; McCarthy \& Goffin, 2001). Research has found that having intermediaries such as recommendation letter writers advocate or promote on one's behalf results in more favorable perceptions and that people can avoid criticism for singing their own praises by having a third-party or agent communicate their competence (Pfeffer, Fong, Cialdini, \& Portnoy, 2006) Similarly, although previous research has suggested that hiring managers perceive some identity disclosures to be inappropriate (Arena \& Jones, 2017), having a letter of recommendation writer provide the disclosure may shield the applicant from negative backlash related to perceptions of inappropriateness. This is in line with theoretical orientations that suggest that having 
others advocate on your behalf represents a specific type of ingratiation tactic designed to increase liking (Jones \& Pittman, 1982). In addition, because intermediaries such as letter writers provide relatively uninvested and emotionally detached perspectives (Rubin \& Sander, 1988), a letter writer who acknowledges an applicant's gender non-binary identity also communicates that this identity is well-known, normalized, and presumably inconsequential to workplace outcomes.

In situations in which both the applicant and letter writer disclose the applicant's non-binary identity (i.e., a "full disclosure" condition), I propose that hiring managers will rate applicants higher than in situations in which only the applicant self-discloses. This "full disclosure" may signal to employers that the disclosed identity and associated disclosure is "normal" for everyone (the applicant, the letter writer, and other former work colleagues). This could happen because by both the applicant and letter writer disclosing the information, it could clarify social norms about how to interact with the applicant (e.g., using the correct pronouns when referring to them). Indeed, research indicates that the clarity of social norms regarding the display of prejudice against various groups predicts how influenced individuals will be to change their attitudes (Zitek \& Hebl, 2004). However, it is reasonable to assume that some job applicants would choose to self-disclose but not ask former supervisors to disclose on their behalf and this may happen for many reasons (e.g., they were not "out" at their previous jobs, they suffered discrimination at their previous job and thus cannot or do not want to ask their former supervisor for a recommendation). As stated previously, I propose that hiring 
managers will rate these applicants lower than in "full disclosure" situations where both the applicant and the letter writer disclose the applicant's non-binary identity.

Hypothesis 2. Job applications in which a non-binary gender identity is disclosed by both the applicant and a recommendation letter writer will receive higher ratings of perceived hireability than job applications in which only the applicant self-discloses.

\section{Supervisor Social Support}

Minority stress theory (Meyer, 1995; 2003; 2015) holds that members of stigmatized groups, especially sexual and gender minorities, are vulnerable to additional negative health and well-being outcomes (e.g., increased anxiety and depression) as a result of chronic life stressors (e.g. discrimination, rejection) beyond those experienced by non-stigmatized groups. According to the theory, certain factors can buffer the effect of these stressors, including social support, which refers to the receipt of help from others (Meyer, 2015). Social support in the workplace is a "meta-construct" conceptualized as encompassing emotional, instrumental, informational, or structural assistance provided by individuals or organizations (Vaux, 1988; House, 1981). Support can be demonstrated to employees in many ways across multiple levels of the organization (Dimoff \& Kelloway, 2017; Huffman et al., 2008). For example, supervisors may provide support by providing tangible resources (e.g., a bonus) or emotional support (e.g., listening to an employee who is distressed) and organizations may provide intangible resources such as supportive work-family policies or flexibility (e.g., Allen, 2001; Thomas \& Ganster, 1995). Having the support of one's supervisor is important because supervisors hold 
power over employees (Frone, 2000) and are viewed as representatives of the organizations they serve, leading their employees to perceive their support as indicative of support from the organizations as well (Rhoades \& Eisenberger, 2002). Leaders' behaviors also help establish norms within a workplace (Eisenberger, Stinglhamber, Vandenberghe, Sucharski, \& Rhodes, 2002; Wayne, Shore, \& Liden, 1997). Indeed, studies have shown that both instrumental support (providing tangible resources, such as time, materials, or skills; House, 1981) and psychosocial support (e.g., education, coaching) are negatively related to work stress (Abdel-Halim, 1982; AbuAlRub, 2004; Ganster et al., 1986; Hagihara et al., 1998; Sanchez, \& Fisher, 1999; Viswesvaran, Witt \& Carlson, 2006) and that employees who feel supported by their managers report higher levels of job satisfaction, job performance, and organizational commitment, and lower levels of absenteeism, stress, burnout, and turnover intentions (AbuAlrub, 2004; Godin \& Kittel, 2004; Lowe et al., 2003; Kurtessis, Eisenberger, Ford, Buffardi, Stewart, \& Adis 2015; Riggle, Edmonson, \& Hansen, 2009; Huffman et al., 2008).

Embedded within the minority stress framework, supervisors may be called on to support stigmatized employees as they navigate additional chronic life stressors associated with their identities. Indeed, research has found that employees may have unique needs relating to social support as a function of their individual identities (Wortman \& Dunkel-Schetter, 1987). As an example, Wayment and Peplau (1995) proposed that lesbians might value social support related to their personal identity more so than heterosexual women because it supports their feelings of self-worth. Huffman and colleagues (2008) found that between supervisor support, organizational support, and 
coworker support, supervisor support was the only type of support significantly related to job satisfaction, while coworker support was related to life satisfaction and organizational support was related to outness among LGB employees. In the case of non-binary employees, social support may include helping them disclose their gender identities to coworkers, listening and responding to their reports of harassment or discrimination from peers, providing them with transition-related information (e.g., access to health insurance) if needed, and helping enforce name and pronoun use by coworkers. Research on the experience of transgender employees has consistently found that organizational support and coworker support play key roles in transgender employees' job satisfaction, life satisfaction, disclosure behaviors, perceived discrimination, and feelings of authenticity at work (Budge, et al., 2010; Law, Martinez, Ruggs, Hebl, \& Akers, 2011; Martinez et al., 2017; Sawyer \& Thoroughgood, 2017; Sawyer et al., 2017; Schilt, 2006; Schilt \& Connell, 2007, Schilt \& Wiswall, 2008). When organizational support (e.g., the presence of anti-discrimination policies) and coworker support are high, transgender employees report lower perceived discrimination (Ruggs et al., 2015), lower job anxiety and turnover intentions, and higher job and life satisfaction and commitment (Law et al., 2011). A supervisor's display of support toward employees with marginalized identities serves as a role model for and demonstrates inclusion to all employees that the workplace is a welcoming environment. Ultimately, supervisors who feel "willing and able" to provide social support at work are in a position to significantly impact employee mental health, well-being, and performance (Dimoff \& Kelloway, 2017). 
To my knowledge, there has been no research on supervisors' self-reported perceptions of being "willing and able" to provide support. However, is it important to consider how hiring managers, who act as gatekeepers in an organization, perceive prospective employees and the types of support they would need, and their own ability to provide such support. It is reasonable to assume that managers recognize that different groups have unique needs, make assumptions about those needs, and make judgements about their own perceived ability to meet those needs. This means some managers may perceive themselves as being more capable of or willing to provide specific, additional levels of support to stigmatized employees than others, which would have consequences in various contexts (e.g., when providing feedback, mentoring, or coaching; when performing reviews). One such context is hiring; it is likely that if managers believe they cannot provide social support to certain job applicants based on personal attributes or characteristics such as minority status, they will be less likely to hire them. Managers may perceive a lack of ability to provide social support to employees with non-binary gender identities for multiple reasons: (a) a lack of knowledge about transgender and non-binary identities on the hiring manager's part, leading to a lack of confidence that they can provide support, (b) strongly held beliefs in a gender binary and a disbelief in identities that exist in the middle of or do not exist on the gender binary, (c) negative attitudes toward people who violate gender roles associated with the sex they were assigned at birth (King, Winter, \& Webster, 2009), (d) reliance on stereotypes of transgender people as having a mental illness or being otherwise "abnormal" (Gazolla \& Morrison, 2014), and (e) parallel to aversive racism (Gaertner \& Dovidio, 1986), people 
may avoid individuals different from them. Given the high level of stigma associated with transgender people (James et al., 2016), I predict that hiring managers to whom an applicant discloses a non-binary gender identity will perceive themselves to be less capable of providing social support to the prospective employee, and this will lead to lower evaluations and hiring intentions by hiring managers.

Hypothesis 3: Hiring managers that review an application in which a non-binary identity is disclosed will report lower perceived ability to provide support than managers who review applications in which no gender identity is disclosed. Hypothesis 4: Perceived ability to provide social support will be positively related to hiring evaluations.

Hypothesis 5: There will be an indirect effect of disclosure condition on job outcomes via managers' perceived ability to provide social support.

\section{Gender Identity Instability Beliefs}

Disclosing a non-binary identity may evoke negative reactions from others due to a perception that non-binary is not a "real" gender identity. Of the reasons for managers" perceived inability to provide support listed in the previous section, disbelief in identities that fall outside or in the middle of a gender binary is the most theoretically interesting because if that is a mechanism through which hiring discrimination can occur, it may provide insight into how entrenched gender binary expectations are in the workplace. This is also practically interesting because it means there could be remediation strategies for organizations and managers. For example, managers could receive training about 
gender diversity, transgender individuals, and non-binary individuals to remove that barrier or knowledge gap.

Research indicates that people are more tolerant of the idea that gender identity may not be fixed than they are the idea that gender identity is not dichotomous (Connell, 2009; Dozier, 2005, as cited in Fogarty \& Zheng, 2018). This is evident in the results of a recent national survey in which $63 \%$ of non-binary respondents reported that others had dismissed their identity as not being "a real identity" or being "just a phase" (James et al., 2016). This perception of gender non-binary as "not a real identity" is parallel to that of bisexuality; a recent study found that people perceive bisexuality as an "invalid identity," and this perception was accompanied by lower intentions to hire bisexual employees, lower perceptions of person-organization fit, and lower ratings of an applicant's job qualifications (Arena \& Jones, 2017). This commonality is not surprising given that gender non-binary and bisexual individuals are both relatively less understood than transgender and gay and lesbian identities, respectively, and are also perceived to be "inbetween" what most people consider to be binary identities. Perceiving non-binary as an invalid identity likely equates with perceiving it as controllable. Controllability is an important aspect of stigma that predicts responses from others; research indicates that individuals who are viewed as responsible for their stigmas are more likely to be disliked and rejected than individuals whose stigmas are perceived as beyond their control (Jones et al., 1984; Ragins, 2008).

As West and Zimmerman (1987) contended, binary thinking becomes entrenched in institutions such as the workplace, where it is reinforced by practices such as self- 
presentation, dress codes, and bathroom segregation. Adopting a self-presentation in the work environment that does not conform to the individual's sex assigned at birth (or to no clear sex at all) and requesting the use of gender-neutral pronouns (e.g., the singular “they") represents a violation of traditional gender role stereotypes (Heilman \& Eagly, 2008) and also presents a challenge to colleagues who may find such self-presentations and requests confusing and disruptive (Jones, 1984). An important implication of these findings is that non-binary individuals not only suffer penalties for violating roles of the gender they were assigned at birth (Heilman \& Eagly, 2008), but for embodying a gender for which no clear norms exist. Disclosing a gender identity for which there is no established social role (and therefore no scripts to be utilized during interactions) would likely lead to confusion, cynicism, and doubt, and therefore lead gender non-binary individuals to be stereotyped as having an "invalid identity."

I predict that the degree to which a hiring manager holds beliefs that non-binary is not a valid gender identity will impact the indirect relationship between a disclosure of a non-binary identity and hiring outcomes through perceived ability to provide support such that the indirect relationship will be weaker among participants who more strongly believe that non-binary is an invalid identity.

Hypothesis 6. Non-binary gender instability beliefs will moderate the indirect relationship between disclosure condition and perceived ability to provide social support such that the negative effect of reviewing a non-binary applicant on ability to provide support will be stronger among managers who believe that gender non-binary is not a valid identity ${ }^{\text {. }}$ 


\section{Method}

The data for this study were collected over two time points from participants (with a subset of different constructs measured at each time) so as to reduce social desirability and common method biases.

\section{Participants}

A power analysis for a one-way ANOVA with four groups revealed I would need a sample of 128 participants to detect a small effect (.30) at a 95\% confidence level and $80 \%$ power. Additionally, conditional indirect effects simulations by Preacher, Rucker, and Hayes (2007) indicated that in order to obtain a moderate effect size $(r=.39)$ at an alpha of .05 , the sample size $(n)$ for the current study would need to be at least 300 . I therefore aimed to collect a total sample of 500 participants to account for attrition from Survey 1 to Survey 2, as well as careless responding from respondents and subsequent measurement validity issues. I recruited participants via Amazon's Mechanical Turk (MTurk), an online data collection and survey platform on which individuals can receive compensation for completing tasks requested by others. Research has demonstrated that MTurk can produce representative samples and that MTurk participants are often more demographically diverse than those of typical psychological studies such as American college samples and standard Internet samples (Buhrmeister, Kwang, \& Gosling, 2011; Walter, Seibert, Goering, \& O’Boyle, 2018). Additionally, studies have indicated that data obtained from MTurk studies are at least as reliable as those obtained via traditional methods (Ran, Liu, Marchiondo, \& Huang, 2015; Fleischer, Mead, \& Huang, 2015). Indeed, a recent meta-analysis based on 90 independent samples found that that data 
collected on online panels including MTurk had similar psychometric properties and produced criterion validities that converged with those of conventionally sourced data (Walter et al., 2018). Some research indicates that there could be a danger in using crowdsourced study data without restrictions; specifically, Feitosa, Joseph, and Newman (2014) found that crowdsourced data were similar to traditionally-collected data, but only when they were restricted to IP addresses from English-speaking countries. The sample for the current study was therefore restricted to participants within the U.S.. I also utilized MTurk settings to restrict the study to only those participants who had at least a $90 \%$ approval rating on MTurk and had completed 50 or more previous MTurk surveys, which are suggested best practices for ensuring quality data (Bartel-Sheehan \& Pittman, 2016; Peer, Vosgerau, \& Acquisti, 2014). Hillygus, Jackson, and Young (2014) found less bias in frequent responders to online panels than in infrequent survey responders. Participants were also required to speak English.

A total of 493 participants completed the first survey. To recruit participants back for the second survey and be able to match their data from the two surveys, I gathered participants' MTurk worker IDs. Specifically, I utilized query strings and embedded data tools in Qualtrics' Survey Flow to automatically pull each participant's MTurk worker ID into the dataset along with their responses. This allowed me to link responses from the two separate data collections. After data from the first survey were collected, I checked the location of all IP addresses for all participants using an online IP address locator tool and removed 20 who were not from the U.S. Additionally, I removed 47 participants who failed attention check items, which consisted of both instructed response (e.g., "Please 
select 'moderately agree"”) and bogus items (e.g., "I do not understand a word of English.”; see Meade \& Craig, 2012). I then removed 65 cases in which participants failed the first manipulation check item, "What gender was the applicant?" Of the participants who correctly answered the first manipulation check item, almost all also correctly answered the second manipulation check item, "What personal information was revealed?" I removed one case that did not correctly identify the applicant as disclosing a non-binary gender identity and three cases that incorrectly answered that the applicant disclosed having cancer. Finally, I removed one case that was completed in less than 5 minutes (about half the average time spent), resulting in a final sample of 356 participants. I approved and paid these participants $\$ .15$ for their participation before launching the second survey.

Ten days after the first survey was completed, I utilized TurkPrime to invite those 356 participants to take the second survey. Specifically, I posted the second survey as a task on MTurk and utilized TurkPrime's "include/exclude" feature, which makes the task visible only to select MTurkers based on workerID. Additionally, I utilized TurkPrime's "email included workers" feature to send an email directly to each participant of Survey 1 inviting them to take a "new survey" for which they qualified; I did not mention the surveys were related to one another. After three days, I sent a reminder email to anyone who had taken the first survey, but had not yet taken the second survey. A total of 303 of those participants completed the second survey, reflecting an $85 \%$ retention rate. Of those, I removed 15 cases that had $10 \%$ or more missing data and were also missing MTurk completion codes. I removed 10 cases that failed attention checks (e.g., "I have 17 
fingers on my left hand," and "Please select very strongly agree"), resulting in a final sample of 278. I approved and paid these participants $\$ .35$ for their participation within two weeks of completing the survey. I then matched the files from Survey 1 and Survey 2 utilizing SPSS" "merge data files" feature, matching cases based on the values of the MTurk worker ID variable in both data sets.

The final sample $(n=278)$ was predominantly female $(68 \%, n=190)$, heterosexual $(84 \%, n=235)$, had some college education $(37 \%, n=101)$ or a college degree $(37 \%, n=102)$, was employed full-time $(53 \%, n=147)$, and was, on average, 39.96 years of age $(S D=13.74)$. In addition, the majority of participants indicated that they were White $(78 \%, n=218)$, followed by Black/African-American $(8 \%, n=22)$, Asian/Asian-American $(8 \%, n=21)$, Hispanic/Latino $(5 \%, n=13)$, biracial/multiracial $(1 \%, n=4)$, Native American/Alaska Native $(1 \%, n=1)$, and Native Hawaiian/Pacific Islander $(1 \%, n=1)$. Additionally, 4\% $(n=10)$ identified as gay/lesbian, 9\% $(n=10)$ identified as bisexual, $1 \%(n=2)$ identified as transgender, and one participant identified as "other" gender. Furthermore, 25\% $(n=69)$ identified as an LGBT ally, and $25 \%(n=$ 68) reported having a friend or family member who is transgender or non-binary. A majority of participants had managerial experience $(66 \%, n=181)$, with $22 \%(n=62)$ having served in a managerial role for more than six years and 24\% $(n=66)$ currently serving as a supervisor. Almost half of participants $(47 \%, n=132)$ had previous hiring experience.

\section{Procedure}


Both surveys were posted as tasks on MTurk using TurkPrime, an online platform that enables researchers to more easily distribute surveys to targeted individuals and to collect longitudinal data. I collected both surveys in Qualtrics. An overview of the measures by data collection timing is provided in Appendix A.

After indicating consent, participants were able to take the first survey. All participants were told that a marketing services company was testing a new crowdsourced method of hiring and were looking for feedback from web users on candidates for a specific job opening. They were then instructed to read a job description for an entry-level Marketing Coordinator position, review application materials, and provide ratings for one job applicant. Because the majority (61\%) of those who identify as nonbinary fall in the age range of 18-24 (James et al., 2016), a mid-level or higher position may have lower face validity than an entry-level position. Additionally, to avoid occupational stereotyping as a potential confound, this position was chosen because marketing positions are not typically stereotyped as being either a masculine or feminine job (Beggs \& Doolittle, 1993; Cash, Gillen, \& Burns, 1977). Participants were instructed to review the applicant's materials for three minutes before moving on to the applicant rating items, and the survey did not allow them to progress until the end of the threeminute period. The fictional job posting included a brief description and a list of both job responsibilities and qualifications. I randomly assigned participants to one of four experimental conditions with the manipulation embedded within the application materials. The "full disclosure" condition represented a disclosure on the resume, cover letter, and letter of recommendation from a former supervisor, the "self-disclosure only" 
condition represented a disclosure only in the resume and cover letter, and the "other disclosure only" represented no disclosure by the applicant themselves but a disclosure by the former supervisor of the applicant's gender. The "no disclosure" condition contained no disclosure in any application materials (and thus represents a presumably cisgender applicant). Participants then rated the job candidate based on the content of the application materials in terms of overall perceptions of hireability (e.g., likeability, qualifications, intentions to hire). They were also asked to complete items asking about their perceived ability to provide social support to the job candidate. At the end of the survey, participants answered two manipulation check items to ensure the non-binary disclosure was salient in the disclosure conditions. Ten days after the first survey concluded, I posted the second survey to measure participant beliefs about the instability of a non-binary gender identity (as described previously) and collect demographic information.

\section{Materials}

I used an existing job listing on Indeed.com to generate the fictional job posting for a Marketing Coordinator. Because the majority (61\%) of those who identify as nonbinary fall in the age range of 18-24 (James et al., 2016), a mid-level or higher position may have lower face validity than an entry-level position. Additionally, to avoid occupational stereotyping as a potential confound, this position was chosen because marketing positions are not typically stereotyped as being either a masculine or feminine job (Beggs \& Doolittle, 1993; Cash, Gillen, \& Burns, 1977). 
I utilized resume, cover letter, and letter of recommendation templates available online to generate realistic materials in commonly used formats. I thoroughly tested all materials prior to experimentation (see Appendix B for a detailed description of the pilot study). Each of the application materials (i.e, resumes, cover letters, and letters of recommendation) contained the manipulation for disclosure (yes vs. no), and were paired together for each of the four conditions (as described above).

All application materials contained one of two gender-neutral names. I used two different names to ensure that any differences found were not a factor of idiosyncratic features corresponding with any one name. In order to identify two gender-neutral names, I included materials for six names in the pilot study (i.e., Skylar, Alex, Alyx, Phoenix, Scout, and Quinn). Results indicated that the names Alyx and Skylar were the most gender neutral and had the highest manipulation check success rates. Participants correctly identified Skylar as non-binary in disclosure conditions at a higher rates (67\%), compared to all other names (Alyx: 61\%, Scout: 61\%, Quinn: 63\%, Phoenix: 62\%, Alex: $65 \%$ ). Although Alyx was not among the highest passing rates (61\%), the name was perceived as the most gender neutral among all the names. Participants in the control (no disclosure) condition were equally likely to assume that Alyx was either male (7 out of 20 participants) or female (8 out of 20 participants), with five participants assuming the applicant's gender was “other" or "non-binary," indicating that Alyx is relatively gender neutral. Similarly, participants in the Skylar control (no disclosure) condition were equally likely to assume the applicant was either male (11 out of 26$)$ or female (10 out of 26), with five participants assuming the applicants was an "other" or "non-binary" 
gender. Participants in the control (no disclosure) conditions for the other four names were more likely to perceive the applicants as primarily male or female. Based on these data, I determined Skylar and Alyx to be the most gender-neutral names for the study and both had satisfactorily passed manipulation checks in the pilot study. After executing the study, I found no differences within condition as a function of applicant name and thus collapsed across name in subsequent analyses.

\section{Measures}

All items except demographics were measured using 7-point Likert-type scales ranging from $1=$ not at all agree to $7=$ very strongly agree. $I$ created mean scores for each scale. All measures are provided in Appendix A.

Perceived hireability. I measured overall evaluation of applicants with 14 items from a scale created by King, Madera, Hebl, \& Knight (2012). The measure demonstrated acceptable reliability $(\alpha=.95)$.

Perceived ability to provide social support. Hiring manager's perceived ability to provide social support was measured using items from an adapted version of House and Wells' (1978) Social Support scale (Comer, Deeter-Schmelz, \& Ramsey, 1997) and some items developed for this study. Because the original scale was designed to measure one's ratings of multiple sources of support (e.g., supervisor, coworkers, spouse, family and friends), I utilized only supervisor-related items. Although the original scale was not divided into sub-dimensions, careful examination of the original items suggests that four of the items are focused on providing emotional support with work tasks and two of the items are focused on providing tangible support with work tasks. Because social support 
can also include facilitating positive interpersonal relationships among coworkers (particularly for employees with stigmatized identities), I added three items designed to measure this dimension. I also added one item related to the perceived ability to provide support related to the applicant's marginalized identity ("I would be able to help this person if they were to experience issues with discrimination or harassment on the job.") Additionally, because the original scale is focused on one's perceptions of support they receive from others, I made minor wording changes to measure one's perceived ability to provide support to others. Finally, the original scale items were quantity-based (the extent to which each source fulfills a particular supportive function); I changed them to be agreement-based. The reliability coefficient for the social support scale in other research was .84 (Jenkins \& Elliott, 2004). This measure demonstrated acceptable reliability in my data $(\alpha=.95)$.

Instability of non-binary gender identity. Participants' perceptions of the validity of a non-binary gender identity were assessed using eight items adapted for this study from Mohr and Rochlen's (1999) Attitudes Regarding Bisexuality stability subscale to focus on gender stability rather than sexual orientation stability. Higher scores represented beliefs that non-binary was a less stable gender identity. Sample items include "People who call themselves gender non-binary can't decide what gender they want to be" and "Just like male and female, gender non-binary is a stable gender identity." This measure demonstrated acceptable reliability $(\alpha=.94)$.

Demographics. I asked participants to provide standard demographic information including age, gender identity, race/ethnicity, sexual orientation, and education level, as 
well as items related to their employment and managerial experience (i.e., current employment status, current manager status, years managerial experience, previous experience as a hiring manager). To provide further context for study findings, I also asked participants whether they were a member of the LGBTQ community (and if not, whether they considered themselves an LGBTQ ally) and whether they had any friends or family members who identified as transgender or non-binary. 


\section{Results}

Before testing my hypotheses, I examined descriptive statistics and box plots of the final sample to assess for potential outliers for the focal variables. There appeared to be three outliers on hireability ratings, all of whom rated the applicant with average ratings of between 1 and 2. There appeared to be five outliers on the support variable, all of whom reported a very low perceived ability to provide support (less than $\sim 2.25$ on average). Two of the outliers were also outliers on hireability ratings. There were no outliers on the instability variable. I also reviewed histograms to assess normality and checked for skewness and kurtosis. I ran all analyses with and without outliers and it did not change the pattern of results, so I maintained outliers for the analyses.

I found all focal variables to be approximately symmetric (skewness $<=.51$., $S E=$ $.15)$ and within acceptable kurtotic limits $(-2>k<2)$. Because the group sizes were not roughly equal ( no disclosure $=82$, full disclosure $=73$, self-disclosure $=56$, other disclosure $=67$ ), I also inspected the data for multicollinearity and homoscedasticity. Levene's test showed that the variances for Gender Non-Binary Instability Beliefs were not equal, $F(3,274)=.46, p=0.01$. The other variables did not violate the assumption $(p$ $>$.05). To test for multicollinearity, I obtained the variance inflation factor (VIF) for both

Gender Non-Binary Instability Beliefs and Perceived Ability to Provide Support, which were below $10(\mathrm{VIF}=1.03$ for both $)$, indicating low concern for multicollinearity.

Table 1 presents descriptive statistics and intercorrelations between the focal variables. All of the variables were positively correlated and significant. Table 2 shows the means and standard deviations of all study variables by disclosure condition. 


\section{Hypothesis Testing}

I conducted all between-groups hypothesis tests using a priori contrast analyses. Specifically, I created a variable to identify the condition and conducted a one-way ANOVA on this variable with contrasts constructed to assess specific hypothesized comparisons. All analyses were performed using SPSS statistical software.

Hypothesis 1 proposed that job applications that included the disclosure of a nonbinary gender identity would receive lower perceptions of hireability than job applications that did not include a gender identity disclosure. I constructed a contrast that examined differences in hireability ratings between the no disclosure condition and all three other conditions combined. This hypothesis was not supported, $F(1,270)=2.60, p$ $=.11, \eta_{p}^{2}=.01$.

Hypothesis 2 stated that job applications in which a non-binary gender identity was disclosed by both the applicant and a recommendation letter writer ("full disclosure") would receive higher ratings of perceived hireability than job applications in which only the applicant self-disclosed. This hypothesis was not supported, $F(1,270)=1.02, p=.31$, $\eta_{p}^{2}=.00$

Hypothesis 3 stated that hiring managers that reviewed an application in which a non-binary identity was disclosed would report lower perceived ability to provide support than managers who reviewed applications in which no gender identity was disclosed. The hypothesis was not supported, $F(1,270)=0.00, p=.96, \eta_{p}{ }^{2}=.00$. 
Hypothesis 4 stated that perceived ability to provide social support would be positively related to hiring evaluations. As expected, the variables were strongly correlated, $r=.73, p<.01$.

Hypothesis 5 stated that there would be an indirect effect of disclosure condition on hireability through managers' perceived ability to provide social support. I examined these hypothesized relationships utilizing Hayes' PROCESS Macro (Hayes, 2018; Model 4) with percentile bootstrap confidence intervals using 10,000 samples. Given that this predicted relationship is based on disclosure method, I entered Disclosure as a multicategorical predictor with the no disclosure condition as the reference category. Results indicated that the indirect effects of disclosure condition on hireability ratings through perceived ability to provide support were not significant for any comparison: self-only vs. no disclosure, $b=-0.05, S E=0.12,95 \%$ CI $[-0.29,0.19]$, other disclosure vs. no disclosure, $b=-0.05, S E=0.12,95 \%$ CI [-0.29, 0.19], and full disclosure vs. no disclosure, $b=0.08, S E=0.12,95 \%$ CI $[-0.18,0.32]$. No other comparisons were significant (e.g., other disclosure vs. full disclosure). Thus, Hypothesis 5 was not supported. See Table 4 for full results.

Hypothesis 6 stated that non-binary gender instability beliefs would moderate the indirect relationship between disclosure condition and perceived ability to provide social support such that the negative effect of reviewing a non-binary applicant on ability to provide support would be stronger among managers who believe that gender non-binary is not a valid identity. To test this hypothesis, I utilized PROCESS Macro Model 7 (Hayes, 2018) for conditional indirect effects, with disclosure method as the independent 
variable (multicategorical with "no disclosure" as the reference group), perceived ability to provide support as the mediator, non-binary gender instability beliefs as the moderator, and perceived hireability as the outcome. For the sake of parsimony, I examined the effect of stability at the 16th, 50th, and 84th percentile values of the moderator, which is the default in PROCESS. The results of these analyses are presented in Table 4.

As demonstrated in Table 4, there was not a significant effect of instability beliefs in the indirect effect that compares the self-only disclosure condition to the no disclosure condition. Specifically, the confidence intervals for the indirect effects include zero for those who hold low, average, and high instability beliefs. When comparing the other disclosure condition to the no disclosure condition, the confidence intervals did not contain zero for individuals with particularly unstable beliefs (more negative attitudes), indicating that there was a negative effect of someone else disclosing an applicant's gender identity (compared to no disclosure) among participants with more negative attitudes. Importantly, the index of moderated mediation, which provides a statistical test of the strength of the moderated mediation effect, was significant, $b=-0.16, S E=0.07$, $\mathrm{CI}=[-0.29,-0.02]$

When comparing the full disclosure condition to the no disclosure condition, the confidence intervals includes zero across all three levels of the moderator, indicating that the mediation was not impacted by instability beliefs. None of the other comparisons were significant. Together, these results suggest that Hypothesis 6 was partially supported in the comparison between participants who viewed an applicant whose gender identity was disclosed in a letter of recommendation only and those whose gender 
identity was not disclosed. To explore this phenomenon further, I completed exploratory post-hoc analyses.

\section{Exploratory Analyses}

To understand the nature of the conditional indirect effect revealed in the comparison between those in the other disclosure condition and those in the no disclosure condition I conducted a moderation analysis with perceived ability to provide support as the outcome. This analysis revealed that the interaction term for the comparison between these two conditions was significant, $b=-0.22, p=.02, \mathrm{CI}=[-0.41,-0.03]$. None of the other interaction terms were significant. I used the plot function in PROCESS to explore the nature of this interaction, which is depicted in Figure 2. This shows that the negative effect of disclosure of one's gender identity in a letter of recommendation leads to lower perceptions of ability to provide support among participants with relatively negative attitudes about non-binary being a stable gender identity. 


\section{Discussion}

The purpose of the current study was to examine how disclosing a non-binary gender identity when applying for jobs influences hiring outcomes. Specifically, the study assessed how hiring managers' beliefs about non-binary gender identities impacted their perceived ability to provide social support to prospective applicants, and how those perceptions subsequently impacted their hiring evaluations toward applicants who disclose a non-binary gender identity. Additionally, this study examined how these outcomes may differ depending on the method of disclosure. By focusing on non-binary individuals, this study sought to extend the existing research on transgender individuals at work, which had previously treated them as a monolithic group (e.g., Law et al., 2011; Martinez et al., 2017; Thoroughgood et al., 2017).

Contrary to my predictions, there was not a significant difference in hireability ratings or perceived ability to provide support between applicants who disclosed a nonbinary identity in their application materials and those who did not. These findings suggest that participants did not differentially evaluate job applicants on the basis of having or disclosing a non-binary gender and that hiring managers did not report feeling less able to support non-binary employees based on their gender identity. One possible explanation for these finding is that participants in my sample held more egalitarian views. That would be inconsistent, however, with a substantial body of research providing evidence that people who hold stigmatized identities experience discrimination in selection contexts (e.g., Bertrand \& Mullainathan, 2004; King et al., 2006; also see Baert, 2017 for an exhaustive list). Relevant to the current study, past research has also 
demonstrated that individuals whose gender identities and/or expressions do not align with the sex they were assigned at birth suffer hiring discrimination (e.g., Reed, Franks, \& Scherr, 2015; Tilcsik, 2011; Weichselbaumer, 2003). Further, these results conflict with national survey findings indicating high frequencies of workplace discrimination and harassment for transgender and non-binary individuals (James et al., 2016).

I suspect this finding may be due to a few factors. One important reason could be the manipulations themselves. Participants were required to spend three minutes reviewing all application materials on the same screen. The combination of all three materials may have presented a complex task for participants trying to absorb the information and form evaluative judgements. Additionally, because the materials were presented on the same screen, participants needed to scroll down in order to read all three materials. This may have reduced the saliency of the applicant's gender identity compared to the details of the applicant's prior work experience and qualifications contained in three separate materials they were asked to review. Further, participants were not asked to rate applicants as if they were the hiring manager. The cover story was that a fictional company was looking for feedback from web users on a new, "crowdsourced method of hiring"; therefore, participants may not have truly put themselves in the place of a hiring manager and rated the applicants as judiciously as they would have rated actual prospective direct reports.

Another potential explanation for the lack of hiring discrimination may be due to the homogeneity of the study's sample (68\% female, $78 \%$ White, $84 \%$ heterosexual; $66 \%$ previous managerial experience). Past research indicates that women may discriminate 
less in selection contexts than men do (e.g., Pichler \& Varma, 2010). It is also reasonable to assume that women, as a class of individuals who have themselves experienced more hiring discrimination compared to men (Petersen, Saporta, \& Seidel, 2000), would be less likely than men to discriminate against applicants based on gender. Indeed, some researchers have argued that women managers may act as "change agents" by promoting more equitable work environments and rarely perpetrating discrimination and harassment (Bell, McLaughlin, \& Sequeira, 2002). My results could reflect these more equitable attitudes. Additionally, 25\% of my entire sample $(n=69)$ identified as an LGBTQ ally and $25 \%(n=68)$ reported having a friend or family member who is transgender or nonbinary, which could have influenced the outcomes. Having a friend or family member who is transgender or non-binary would likely predict lower levels of hiring discrimination of individuals holding those identities and higher levels of perceived ability to provide support to those individuals.

There was also not a significant difference in hireability ratings between applicants who self-disclosed a non-binary identity in their application materials compared to those whose letter of recommendation writers also disclosed on their behalf ("full disclosure"). This finding was contrary to my prediction, based on theories of impression management, that hiring managers would rate applicants higher when both the applicant and a former supervisor disclosed the information, serving to normalize the disclosure. Although the results did not reach significance, it should be noted that the data were trending in the expected direction. Specifically, the mean hireability score for the "full disclosure" condition was the highest of the disclosure groups $(M=4.87, S D=$ 
$1.20)$, and that of the self-disclosure group was the lowest $(M=4.60, S D=1.08)$. On the whole, hiring managers rated applicants more favorably in situations where a third party also disclosed the applicant's non-binary identity, though this finding was not significant.

As expected, a manager's perceived ability to provide support to a prospective employee significantly correlated with hireability ratings. This indicates that when hiring managers perceive they are able to support a prospective employee, they are more likely to hire them. To my knowledge, past research has not examined the impact on hiring outcomes of hiring manager's perceived ability to provide support to applicants.

The hypothesized indirect effect model, with gender non-binary status predicting hireability due to perceived ability to provide support was not significant. This suggests that a hiring manager's perceived ability to provide support to a prospective applicant did not help explain hireability ratings.

The hypothesized moderation effect was significant for only one of the three disclosure conditions. The significant negative effect of someone else disclosing an applicant's gender identity (compared to no disclosure) among participants with more negative attitudes about gender non-binary individuals is intriguing. When a personal reference disclosed an applicant's gender identity to a prospective future employer who held a belief that non-binary is not a "real" gender identity, participants were more likely to feel they would not be able to support the applicant. A likely explanation for this finding is that people with low non-binary gender stability beliefs (i.e., those who do not belief non-binary is a "real" gender identity) may feel less equipped to support an applicant when the applicant does not also express who they are and what they need 
directly (i.e., the use of they/them pronouns). In such a situation, when the hiring manager learns of the person's identity from a third party, but not directly from the person holding the identity as well, and the hiring manager does not believe the identity is a valid gender identity, that hiring manager may assume the individual is not comfortable or secure in their gender identity in some way (i.e., is confused, ashamed, or otherwise psychologically maladjusted). This is line with previous research that found that perceptions of an applicant's psychological well-being mediated the effect of acknowledgment timing on hiring-related outcomes for applicants with physical disabilities. (Hebl \& Skorinko, 2005). The ambiguity created by the lack of disclosure by the applicant in the presence of third-party disclosure may lead the manager to perceive the prospective hire will have more needs than other applicants, or will have unique needs that would be more challenging to support as their supervisor. Additionally, this finding supports past research that found that people often learn about others' stigmatized identities through indirect means such as gossip (Ambady, Hallahan, \& Conner, 1999; Colgan, Creegan, McKearney, \& Wright, 2007), and that this knowledge may lead to negative work outcomes for individuals who do not also self-disclose (Sabat et al., 2017). In line with this prior research, this finding suggests that it is more harmful to hireability outcomes when a letter of recommendation writer discloses one's non-binary identity in a selection context without also self-disclosing.

\section{Theoretical and Practical Implications}

This study offers several theoretical and practical implications. First, it contributes to the gender discrimination and transgender literatures by disentangling gender role 
violation (i.e., not conforming to traditional gender norms and social roles associated with one's sex at birth, and experiencing consequences as a result) from gender invalidation processes (i.e., one's identity being dismissed due to not conforming to the gender binary at all). To my knowledge, this has not been distinguished in previous studies and thus represents an extension to previous research on transgender employees and broader gender discrimination work.

Second, this study extends past research (e.g., Martinez et al., 2017) on the experiences of transgender employees in that although existing research has focused on the experiences of people who transition from one end of the gender binary to the other, this research instead focuses exclusively on those who do not identify along the gender binary at all. By better understanding the experiences of this subset of the transgender community, scholars can continue to explore the distinct forms of prejudice and discrimination various groups face and their explanatory mechanisms. Additionally, the existing transgender disclosure research has not explored the impact of disclosure method on outcomes. By doing so, this study opens up new avenues for future research that takes into account other variables that may influence the perceptions of interaction partners in disclosure processes. Further, although many studies of transgender individuals' experiences at work involve self-reported experiences, this study captured others' attitudes toward and perceptions of non-binary individuals directly. Moreover, the current research examined manager's perceived ability to provide support to non-binary employees, which has previously been unexplored in the transgender literature. 
Third, this research contributes to the existing stigma literature by delineating certain situations in which-and causal mechanisms through which-prejudice may surface. Results of qualitative interviews (Hamilton \& Martinez, 2019), which informed this study, provided evidence that non-binary individuals experienced frequent discrimination and dismissal of their identities by coworkers and supervisors, and anxiety about future selection experiences. Although the results of this study did not fully corroborate those findings, there was evidence that disclosing a non-binary identity in a certain way (i.e., through a third party such as a professional reference) may lead to negative outcomes (i.e., hiring managers feeling less able to provide support to those individuals) for some participants (i.e., people who believe that non-binary is less of a "real" identity).

Fourth, the primary finding of this study-that certain methods of disclosure in the selection context could lead to worse outcomes than others depending on the gender stability beliefs of the hiring manager-adds to the existing disclosure literature. To date, much of the disclosure research, including research on transgender employees, has treated disclosure as a dichotomous variable and examined the antecedents and outcomes of disclosing to coworkers. To my knowledge, there has been no previous research on outcomes of self-disclosing one's stigmatized identity as compared to having one's identity disclosed by others. This study therefore provides some initial evidence that the way in which one's identity becomes known to relevant others (i.e., supervisors, coworkers, or prospective employers) impacts disclosure outcomes. 
This study also offers some practical implications. First, the finding that some managers may feel less able to support non-binary individuals under certain circumstances (i.e., when someone else discloses the individuals' identity) may have broader implications in a workplace. Specifically, the study provides evidence that organizations may need to educate managers on non-binary identities and the experiences of non-binary individuals to enhance their confidence in supporting non-binary employees. Additionally, by focusing on fostering manager's knowledge of non-binary identities and skills toward supporting non-binary employees, organizations can work to ensure their climates are inclusive of all genders.

Another practical implication from this study is that if hiring managers feel they can support a prospective employee, they will be more likely to hire them. The training literature has shown that leaders can be effectively trained to better support their employees (Dimoff \& Kelloway, 2016). This suggests that if managers are given knowledge and awareness-based training of non-binary gender identities and unique needs of those individuals, their confidence in supporting members of that group will increase. As a result, managers will be less likely to discriminate against non-binary job applicants when making hiring decisions. Trainings and toolkits aimed at addressing managers' perceived inability to support non-binary employees should thus improve hiring outcomes for non-binary job seekers overall.

Finally, the results of this study carry implications for non-binary job applicants. Many of the people I interviewed prior to this study shared that they would likely disclose in application materials so as to reduce awkwardness in future in-person 
interactions and preempt future discrimination on the job. The findings from this study can help non-binary individuals make more informed disclosure decisions. In situations where the individual wants to disclose in application materials to achieve greater authenticity in future interactions, results indicate that the best outcomes would result from "full disclosure," and the worst outcomes would result from having someone else disclose on your behalf without self-disclosure. In other words, a primary implication of this study seems to be that having consistent information across one's application materials drives better outcomes than having discordant information.

\section{Limitations and Future Directions}

The examination of how hiring managers rated non-binary job seekers based on a disclosure in job application materials offers ample opportunities for further exploration. First, the current study only examined one of many possible moderators for why managers would perceive themselves to be less able to provide social support to nonbinary employees: perceiving non-binary as an invalid identity. Other moderators may include political beliefs (e.g., Social Dominance Orientation, Right Wing Authoritarianism), a reliance on stereotypes (e.g., that transgender people are mentally ill or "abnormal"), or a rigid belief in traditional gender roles. Additionally, other moderators for why managers would perceive themselves as more able to provide social support might include having a friend or family member who is transgender or nonbinary, or identifying as an LGBT ally. Future studies should analyze these as other factors influencing managers' perceived ability to provide support. 
Future studies could also examine the impact of in-person disclosures. It is possible that many people who identify as non-binary would wait until an in-person experience to disclose their gender identity. Qualitative interviews indicate that many non-binary people would wait until an in-person interview to disclose so that they could better assess the organizational climate before disclosing. Others reported they may wait until after being hired to disclose. Future research could also examine the impact of disclosure timing (e.g., in application materials, during a phone interview, or during an in-person interview; before vs. after being hired) on hiring and other job outcomes. 


\section{Conclusion}

Awareness of issues faced by transgender people has steadily grown over the last decade. However, non-binary individuals-a subset of the transgender community-remain under-researched and thus the least understood by scholars. National surveys have found that non-binary individuals report experiencing negative reactions from coworkers, including being told non-binary is a not a "real" identity, and also experiencing negative work and personal outcomes (James et al., 2016). The current study tested hiring manager evaluations of people who disclosed a non-binary gender identity in job application materials and tested explanatory mechanisms behind those evaluations. Compared to not disclosing a non-binary identity, disclosing did not lead to more negative outcomes. Future research should continue to explore the experiences of non-binary employees in workplace contexts. 


\section{Tables}

Table 1

Inter-item correlations and reliabilities between study variables $(n=278)$

\begin{tabular}{|c|c|c|c|c|c|}
\hline Variable & $\mathrm{M}$ & SD & 1 & 2 & 3 \\
\hline 1. Hireability & 4.79 & 1.08 & $(.95)$ & & \\
\hline 2. Perceived Ability to Provide Support & 5.07 & 1.13 & $.73^{* *}$ & $(.95)$ & \\
\hline $\begin{array}{l}\text { 3. Instability of Non-Binary Gender } \\
\text { Identity }\end{array}$ & 3.31 & 1.95 & $-.14^{*}$ & $-.17 * *$ & (.94) \\
\hline
\end{tabular}

Note. Cronbach's alpha reliability values are on the diagonal.

$* p<.05$.

$* * p<.01$. 
Table 2

Group means and standard deviations for all study variables

\begin{tabular}{|c|c|c|c|c|c|c|c|c|c|c|}
\hline \multirow[b]{2}{*}{ Variable } & \multicolumn{2}{|c|}{$\begin{array}{c}\text { Total } \\
(n=278)\end{array}$} & \multicolumn{2}{|c|}{$\begin{array}{c}\text { No Disclosure } \\
\quad(n=82)\end{array}$} & \multicolumn{2}{|c|}{$\begin{array}{l}\text { Full Disclosure } \\
\qquad(n=73)\end{array}$} & \multicolumn{2}{|c|}{$\begin{array}{c}\text { Self } \\
(n=56)\end{array}$} & \multicolumn{2}{|c|}{$\begin{array}{c}\text { Other } \\
(n=67)\end{array}$} \\
\hline & $M$ & $S D$ & $M$ & $S D$ & $M$ & $S D$ & $M$ & $S D$ & $M$ & $S D$ \\
\hline Hireability & 4.79 & 1.08 & 4.94 & 0.95 & 4.87 & 1.2 & 4.6 & 1.08 & 4.68 & 1.09 \\
\hline Perceived Ability to Provide Support & 5.07 & 1.13 & 5.08 & 0.85 & 5.18 & 1.33 & 5.01 & 1.11 & 5.00 & 1.23 \\
\hline Stability of Non-Binary Gender & 3.31 & 1.95 & 3.45 & 1.89 & 3.21 & 2.02 & 3.44 & 2.05 & 3.14 & 1.89 \\
\hline
\end{tabular}

Note: $M=$ mean, $S D=$ standard deviation. 
Table 3

Bootstrap (10,000 samples) mediation analyses for the effect of disclosure condition on hireability outcomes through perceived ability to provide support.

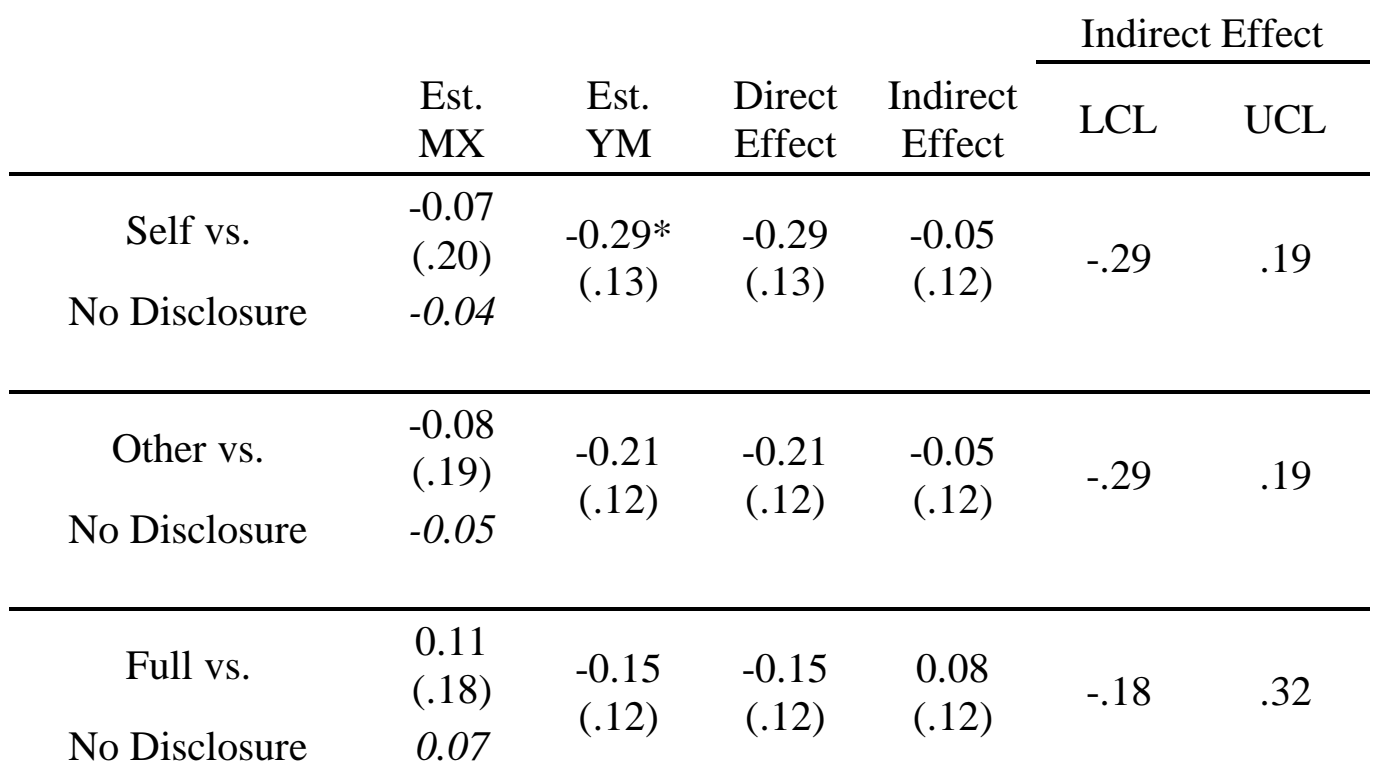

Note: Est. MX = bootstrapped estimate of the path from disclosure condition to perceived ability to provide support. Est. YM = bootstrapped estimate of path from perceived ability to provide support to hireability. $\mathrm{LCL}=$ lower confidence limit. $\mathrm{UCL}=$ upper confidence limit. Standard errors of the bootstrapped estimates appear in parentheses. Standardized beta estimates appear in italics. One thousand non-bias corrected bootstrap samples. $* \mathrm{p}<.05 . * * \mathrm{p}<.01 . * * * \mathrm{p}<.001$ 
Table 4

Bootstrapped (10,000) conditional indirect effects analyses for the effect of non-binary gender stability beliefs on the influence of disclosure condition on hireability outcomes through perceived ability to provide support $(n=278)$

\begin{tabular}{|c|c|c|c|c|c|c|c|}
\hline \multirow[b]{2}{*}{ Disclosure Group } & \multirow[b]{2}{*}{ Instability } & \multirow[b]{2}{*}{ Est. MX } & \multirow[b]{2}{*}{ Est. YM } & \multirow[b]{2}{*}{ Direct Effect } & \multirow[b]{2}{*}{$\begin{array}{l}\text { Indirect } \\
\text { Effect }\end{array}$} & \multicolumn{2}{|c|}{ Indirect Effect } \\
\hline & & & & & & LCL & UCL \\
\hline Self vs. & High & $-0.16(.09)$ & $-0.29 *(.13)$ & $-0.29 *(.13)$ & $\begin{array}{l}0.22 \\
(.19)\end{array}$ & -.13 & .59 \\
\hline \multirow[t]{2}{*}{ No Disclosure } & & & 0.03 & 0.03 & & & \\
\hline & Low & & & & $\begin{array}{r}-0.29 \\
(.21) \\
\end{array}$ & -.70 & .10 \\
\hline Other vs. & High & $\begin{array}{c}-0.22 * \\
(.09)\end{array}$ & $-0.21(.12)$ & $-0.20(.12)$ & $\begin{array}{l}0.28 \\
(.20)\end{array}$ & -.10 & .67 \\
\hline \multirow[t]{2}{*}{ No Disclosure } & & 0.02 & & & & & \\
\hline & Low & & & & $\begin{array}{c}-0.43^{*} \\
(.20) \\
\end{array}$ & -.83 & -.05 \\
\hline Full vs. & High & $-0.07(.09)$ & $-0.15(.11)$ & $-0.15(.12)$ & $\begin{array}{l}0.19 \\
(.18)\end{array}$ & -.16 & .54 \\
\hline No Disclosure & Low & & & & $\begin{array}{l}-0.05 \\
(.23)\end{array}$ & -.53 & .38 \\
\hline
\end{tabular}

Note: Est. MX = bootstrapped estimate of the path from disclosure method to perceived ability to provide support. Est. YM = bootstrapped estimate of path from perceived ability to provide support to hireability outcomes. $\mathrm{LCL}=$ lower confidence limit. UCL $=$ upper confidence limit. The estimates of Est. MX are the same across outcomes. Standard errors of the bootstrapped estimates appear in parentheses. Indices of moderated mediation were not significant for all analyses. One thousand non-bias corrected bootstrap samples.

$* p<.05 . * * p<.01 . * * * p<.001$ 


\section{Figures}

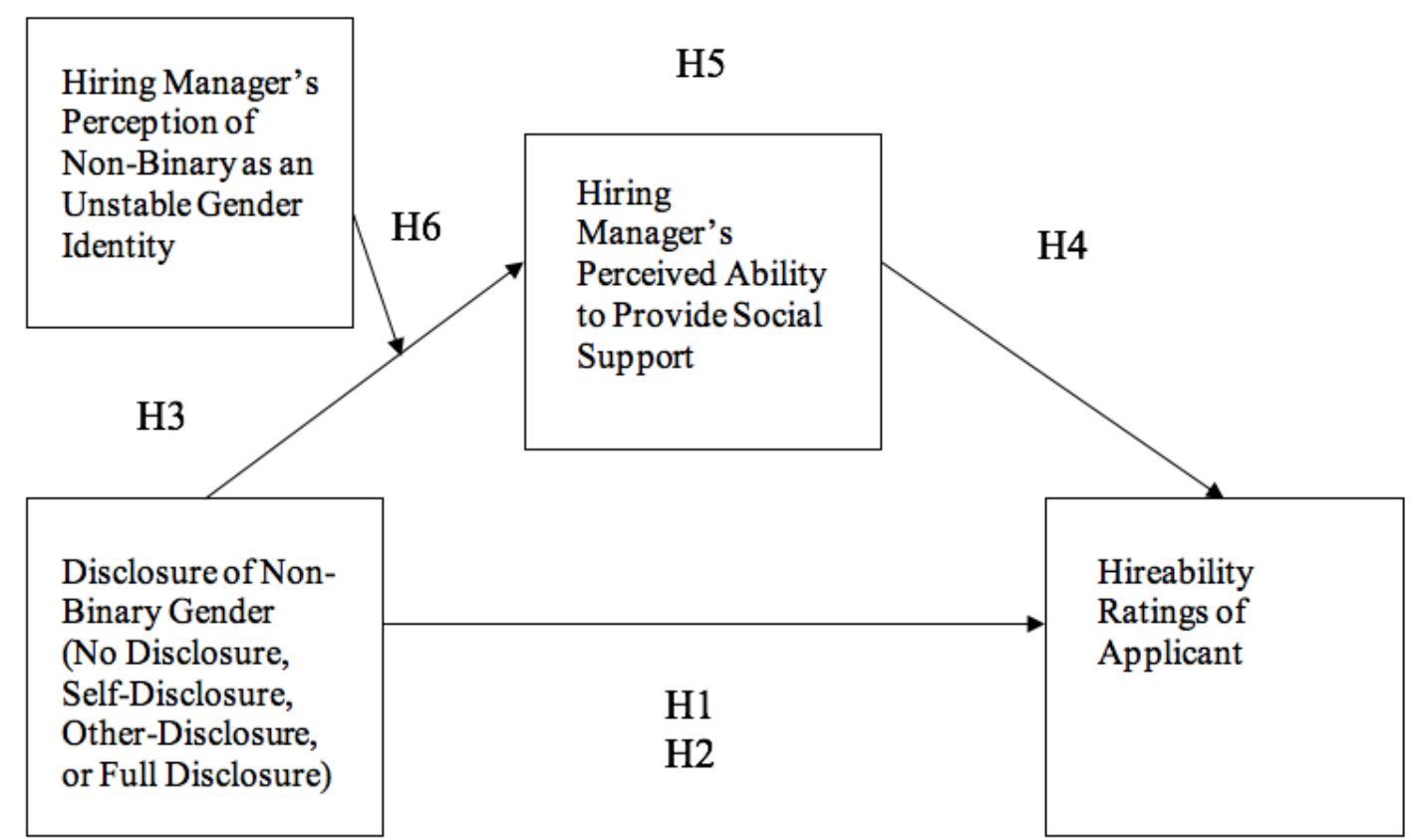

Figure 1. Hypothesized Moderated Mediation Model. 


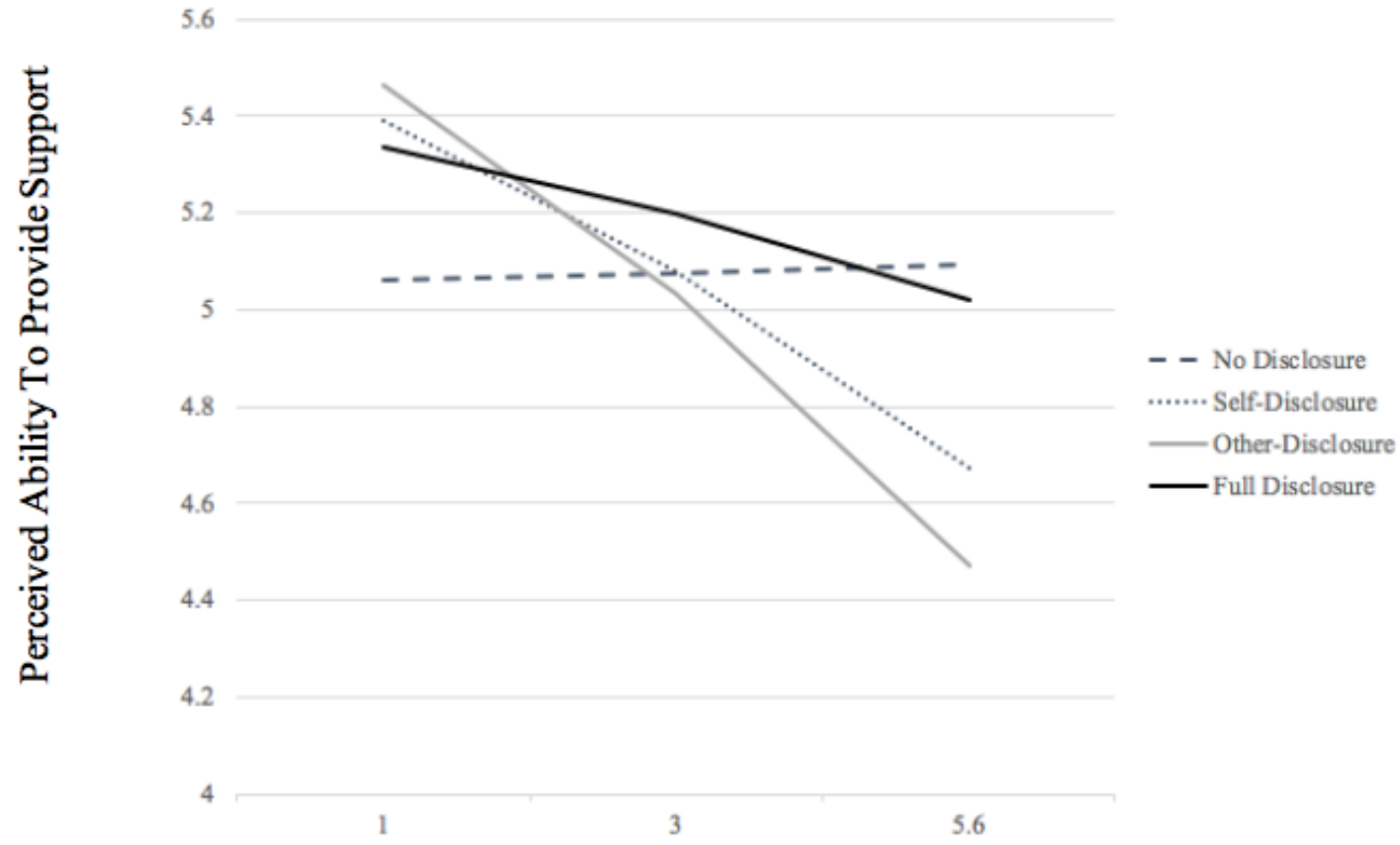

Non-Binary Gender Instability Beliefs

Figure 2. Visual representation of moderation results from exploratory analyses. Points along the horizontal axis represent the 16th, 50th, and 84th percentiles of the moderator. 


\section{Endnotes}

1. It is likely that the moderation will also influence the direct effect of disclosure condition on outcomes such that the lower a manager's belief in non-binary identities, the lower their ratings of a non-binary candidate's hireability. I have not included a hypothesis related to this, however, because it is not a focal aspect of this thesis. 


\section{References}

Abdel-Halim, A. A. (1982). Social support and managerial affective responses to job stress. Journal of Occupational Behavior, 3, 281-295.

AbuAlRub, R. F. (2004). Job stress, job performance, and social support among hospital nurses. Journal of Nursing Scholarship, 36, 73-78.

Allen, T. D. (2001). Family-supportive work environments: The role of organizational perceptions. Journal of Vocational Behavior, 58, 414-435.

Allport, G. W. (1954). The nature of prejudice. Cambridge, MA: Perseus Books.

Ambady, N., Hallahan, M., \& Conner, B. (1999). Accuracy of judgments of sexual orientation from thin slices of behavior. Journal of Personality and Social Psychology, 77, 538-547.

Arena, D. F., \& Jones, K. P. (2017). To "B" or not to "B": Assessing the disclosure dilemma of bisexual individuals at work. Journal of Vocational Behavior, 103, 86-98.

Baert, Stijn (2017). Hiring discrimination: An overview of (almost) all correspondence experiments since 2005, IZA Discussion Papers, No. 10738, Institute of Labor Economics (IZA), Bonn.

Barling, J., MacEwen, K. E. \& Pratt, L. I. (1988). Manipulating the type and the source of social support: An experimental investigation. Canadian Journal of Behavioral Science, 20, 140-53.

Bartel-Sheehan, K., \& Pittman M. (2016). Amazon's Mechanical Turk for academics. Irvine, CA: Melvin \& Leigh. 
Beggs, J. M., \& Doolittle, D. C. (1993). Perceptions now and then of occupational sex typing: A replication of Shinar's 1975 study. Journal of Applied Social Psychology, 23, 1435-1453.

Bell, M. P., McLaughlin, M. E., \& Sequeira, J. M. (2002) Discrimination, harassment, and the glass ceiling: Women executives as change agents. Journal of Business Ethics, 37, 65-76.

Blau, P. M. (1964). Exchange and power in social life. New York, NY: Wiley.

Bolino, M. C., Kacmar, K. M., Turnley, W. H., \& Gilstrap, J. B. (2008). A multi-level review of impression management motives and behaviors. Journal of Management, 34, 1080-1109. https://doi.org/10.1177/0149206308324325

Brem, C., Lampman, C., \& Johnson, M. (1995). Preparation of applications for academic positions in psychology. American Psychologist, 50, 533-537. http://doi.org/10.1037/0003-066X.50.7.533

Brown, C., Dashjian, L. T., Acosta, T. J., Mueller, C. T., Kizer, B. E., \& Trangsrud, H. B. (2012). The career experiences of male-to-female transsexuals. The Counseling Psychologist, 40, 868-894. https://doi.org/10.1177/0011000011430098

Buhrmester, M., Kwang, T., \& Gosling, S. D. (2011). Amazon's Mechanical Turk: A new source of inexpensive, yet high-quality, data? Perspectives on Psychological Science, 6, 3-5. https://doi.org/10.1177/1745691610393980

Burns, G. N., Christiansen, N. D., Morris, M. B., Periard, D. A., \& Coaster, J. A. (2014). Effects of applicant personality on resume evaluations. Journal of Business and Psychology, 29, 573-591. https://doi.org/10.1007/s10869-014-9349-6. 
Bye, H. H., Horverak, J. G., Sandal, G. M., Same, D. L., \& van de Vigver, F. J. R. (2014). Cultural fit and ethnic background in the job interview. International Journal of Cross Cultural Management, 14, 7-26. http://dx.doi.org/10.1177/1470595813491237

Budge, S. L., Tebbe, E. N., \& Howard, K. A. S. (2010). The work experiences of transgender individuals: Negotiating the transition and career decision-making processes. Journal of Counseling Psychology, 57, 377-393. http://dx.doi.org/10.1037/a0020472

Burns, G. N., Christiansen, N. D., Morris, M. B., Periard, D. A., \& Coaster, J. A. (2014). Effects of applicant personality on resume evaluations. Journal of Business and Psychology, 29, 573-591. http://dx.doi.org/10.1007/s10869-014-9349-6.

Cascio, W. F., \& Aguinis, H. (2004). Applied Psychology in Human Resource Management (6th ed.). Upper Saddle River, NJ: Prentice Hall.

Cash, T. F., Gillen, B., \& Burns, D. S. (1977). Sexism and “'beautyism”' in personnel consultant decision making. Journal of Applied Psychology, 14, 69-81. http://doi.org/10.1037/0021-9010.62.3.301

Cialdini, R. B., Borden, R. J., Thorne, A., Walker, M., Freeman, S., \& Sloan, L. (1976). Basking in reflected glory: Three (football) field studies. Journal of Personality and Social Psychology, 34, 366-375.

Cialdini, R. B., \& De Nicholas, M. E. (1989). Self-presentation by association. Journal of Personality and Social Psychology, 57, 626-631.

http://doi.org/10.1037/0022-3514.57.4.626 
Clair, J. A., Beatty, J. E., \& Maclean, T. L. (2005). Out of sight but not out of mind: Managing invisible social identities in the workplace. Academy of Management Review, 30, 78-95. http://doi.org/10.5465/AMR.2005.15281431

Colgan, F., Creegan, C., McKearney, A., \& Wright, T. (2007). Equality and diversity policies and practices at work: Lesbian, gay and bisexual workers. Equal Opportunities International, 26, 590-609.

Comer, J. M., Deeter-Schmelz, D. R., \& Ramsey, R. P. (1997). Methods in Sales Research: Considering Sources and Types of Social Support: A Psychometric Evaluation of the House and Wells (1978) Instrument. Journal of Personal Selling \& Sales Management, 17, 49-61. https://doi.org/10.1080/08853134.1997.10754082

Connell, R. W. (2009). Accountable Conduct: 'Doing Gender' in Transexual and Political Retrospect. Gender and Society, 23, 104-111. https://doi.org/10.1177/0891243208327175

Davidson, S. (2016) Gender inequality: Nonbinary transgender people in the workplace. Cogent Social Sciences, 2, 1-12. http://doi.org/10.1080/23311886.2016.1236511

Dimoff, J. K., Kelloway, E. K., \& Burnstein, M. D. (2016). Mental health awareness training (MHAT): The development and evaluation of an intervention for workplace leaders. International Journal of Stress Management, 23, 167-189. https://doi.org/10.1037/a0039479

Dimoff, J. K. \& Kelloway, E. K. (2018). Leaders as resources: How managers and 
supervisors can socially support employees toward better mental health and wellbeing. In: Leading to occupational health and safety: How leadership behaviours impact organizational safety and well-being. Chichester, England: Wiley Blackwell.

Dovidio, J., Major, B., \& Crocker, J. (2000). Stigma: Introduction and overview. In T. Heatherton, R. Kleck, M. Hebl, \& J. Hull (Eds.), The social psychology of stigma: 1-30. New York: Guilford Press.

Dozier, R. (2005). Beards, breasts, and bodies: Doing sex in a gendered world. Gender and Society, 19, 297-316.

Eagly, A. H. (1987). Sex differences in social behavior: A social-role interpretation. Hillsdale, NJ: Lawrence Earlbaum Associates.

Eisenberger, R., Stinglhamber, F., Vandenberghe, C., Sucharski, I. L. \& Rhoades, L. (2002). Perceived supervisor support: Contributions to perceived organizational support and employee retention. Journal of Applied Psychology , 87, 565-73. https://doi.org/10.1037/0021-9010.87.3.565

Ellis, A. P. J., West, B. J., Ryan, A. M., \& DeShon, R. P. (2002). The use of impression management tactics in structured interviews: A function of question type? Journal of Applied Psychology, 87, 1200-1208.

https://doi.org/10.1037/0021-9010.87.6.1200

Feitosa, J., Joseph, D. L., \& Newman, D. A. (2015). Crowdsourcing and personality measurement equivalence: A warning about countries whose primary language is not English. Personality and Individual Differences, 75, 47-52. 
https://doi.org/10.1016/j.paid.2014.11.017

Fleischer, A., Mead, A. D., \& Huang, J. (2015). Inattentive responding in MTurk and other online samples. Industrial and Organizational Psychology, 8, 196-202. https://doi.org/10.1017/iop.2015.25

Flores, A. R., Herman, J. L., Gates, G. J., \& Brown, T. N. T. (2016). How many adults identify as transgender in the United States? Los Angeles, California, CA: The Williams Institute.

Fogarty, A. A., \& Zheng, L. (2018). Gender Ambiguity in the Workplace: Transgender and Gender-Diverse Discrimination. ABC-CLIO.

Frone, M. R. (2000). Interpersonal conflict at work and psychological outcomes: Testing a model among young workers. Journal of Occupational Health Psychology, 5, $246-255$.

Gaertner, S. L., \& Dovidio, J. F. (1986). The aversive form of racism. In J. F. Dovidio \& S. L. Gaertner (Eds.), Prejudice, discrimination, and racism (pp. 61-89). Orlando, FL: Academic Press.

Ganster, D. C., Fusilier, M. R., \& Mayes, B. T. (1986). Role of social support in the experience of stress at work. Journal of Applied Psychology, 71, 102-110. http://doi.org/10.1037/0021-9010.71.1.102

Gazzola, S. B., \& Morrison, M. A. (2014). Cultural and personally endorsed stereotypes of transgender men and transgender women: notable correspondence or disjunction? International Journal of Transgenderism, 15, 76-99. https://doi.org/10.1080/15532739.2014.937041 
Godin, I., \& Kittel, F. (2004). Differential economic stability and psychosocial stress at work: Associations with psychosomatic complaints and absenteeism. Social Science and Medicine, 58, 1543-1553. https://doi.org/10.1016/S02779536(03)00345-9

Hagihara, A., Tarumi, K., \& Miller, A. S. (1998). Social support at work as a buffer of work stress-strain relationship: A signal detection approach. Stress Medicine, 14, 75-81.

Hamilton, K. M. \& Martinez, L. R. (2019, April). Just Pick One: Gender Prescriptions \& Restrictions for Non-Binary Employees. In N. A. Smith, \& A. H. Huffman (Chairs), Beyond the Binary: Extending Organizational Scholarship for Trans \& Nonbinary Workers. Symposium at the 34th annual meeting of the Society for Industrial and Organizational Psychology, National Harbor, MD.

Hamilton, K. M., Park, L. S., Carsey, T. A., \& Martinez, L. R. (2019). "Lez be honest”: Gender expression impacts workplace disclosure decisions. Journal of Lesbian Studies, 23, 1-25. https://doi.org/10.1080/10894160.2019.1520540

Harrison, J., Grant, J., \& Herman, J. (2012). A Gender Not Listed Here: Genderqueers, gender rebels, and otherwise in the National Transgender Discrimination Survey. LGBTQ PolicyJournal at the Harvard Kennedy School.

Hayes, A. F. (2018). Introduction to mediation, moderation, and conditional process analysis. (2nd Ed.). New York, NY: The Guilford Press.

Heatherton, T. F., Kleck, R. E., Hebl, M. R., \& Hull, J. (Eds.). 2000. The social psychology of stigma. New York, NY: The Guilford Press. 
Hebl, M. R., \& Skorinko, J. L. (2005). Acknowledging One's Physical Disability in the Interview: Does “When” Make a Difference? Journal of Applied Social Psychology, 35, 2477-2492. https://doi.org/10.1111/j.1559-1816.2005.tb02111.x

Heilman, M. E., \& Eagly, A. H. (2008). Gender stereotypes are alive, well, and busy producing workplace discrimination. Industrial and Organizational Psychology, 1, 393-398. https://doi.org/10.1111/j.1754-9434.2008.00072.x

Highhouse, S. (2009). Designing experiments that generalize. Organizational Research Methods, 12, 554-566. https://doi.org/10.1177/1094428107300396

Hillygus, D. S., Jackson, N., \& Young, M. (2014). Professional respondents in nonprobability online panels. In M. Callegaro, R. P. Baker, J. Bethlehem, A. S.

Goritz, J. A. Krosnick, \& P. J. Lavrakas (Eds.), Online panel research: A data quality perspective (Vol. 1, 219-237).

Houlis, A. (2017). 6 Ways to Convey Your Gender Pronoun on Job Applications. Retrieved June 13, 2018, from https://fairygodboss.com/articles/6-ways-to-convey-your-gender-pronoun-on-jobapplications

House, J. S. (1981). Work stress and social support. Reading, Massachusetts: AddisonWesley.

Huffman, A. H., Watrous-Rodriguez, K. M., \& King, E. B. (2008). Supporting a diverse workforce: What type of support is most meaningful for lesbian and gay employees? Human Resource Management, 47, 237-253. https://doi.org/10.1002/hrm.20210 
James, S. E., Herman, J. L., Rankin, S., Keisling, M., Mottet, L., \& Anafi, M. (2016). The Report of the 2015 U.S. Transgender Survey. Washington, D.C: National Center for Transgender Equality.

Jenkins, R., \& Elliott, P. (2004). Stressors, burnout and social support: Nurses in acute mental health settings. Journal of Advanced Nursing, 48, 622-631. https://doi.org/10.1111/j.1365-2648.2004.03240.x

Johnson, M., Elam, C., Edwards, J., Tayor, D., Heldberg, C., Hinkley, R., \& Comeau, R. (1998). Medical school admission committee members' evaluations of and impressions from recommendation letters. Academic Medicine, 73, S41-S43.

Jones, E. E., Farina, A., Hastorf, A., Markus, H., Miller, D., \& Scott, R. A. 1984. Social stigma: The psychology of marked relationships. New York, NY: Freeman.

Jones, E. E., \& Pittman, T. S. (1982). Toward a general theory of strategic selfpresentation. In J. Suls (Ed.), Psychological perspectives on the self (pp. 231262). Hillsdale, NJ: Lawrence Erlbaum.

Kelloway, E. K., \& Day, A. L. (2005). Building healthy workplaces: What we know so far. Canadian Journal of Behavioural Science, 37, 223-235. https://doi.org/10.1037/h0087259

King, E. B., Mendoza, S. A., Madera, J. M., Hebl, M. R., \& Knight, J. L. (2006). What's in a name? A multiracial investigation of the role of occupational stereotypes in selection decisions. Journal of Applied Social Psychology, 36, 1145-1159. http://doi.org/10.1111/j.0021-9029.2006.00035.x

King, M. E., Winter, S., \& Webster, B. (2009). Contact reduces transprejudice: A study 
on attitudes towards transgenderism and transgender civil rights in Hong Kong. International Journal of Sexual Health, 21, 17-34.

https://doi.org/10.1080/19317610802434609

Kurtessis, J. N., Eisenberger, R., Ford, M. T., Buffardi, L. C., Stewart, K. A. \& Adis, C. S. (2015). Perceived organizational support: A meta-analytic evaluation of organizational support theory. Journal of Management, 22, 1-31. http://doi.org/10.1177/0149206315575554

Landrum, R., Jeglum, E., \& Cashin, J. (1994). The decision-making process of graduate admissions committees in psychology. Journal of Social Behavior and Personality, 9, 239-248.

Law, C. L., Martinez, L. R., Ruggs, E. N., Hebl, M. R., \& Akers, E. (2011). Transparency in the workplace: How the experiences of transsexual employees can be improved. Journal of Vocational Behavior, 79, 710-723. https://doi.org/10.1016/j.jvb.2011.03.018

Levitt, H. M., \& Ippolito, M. R. (2014). Being transgender: Navigating minority stressors and developing authentic self-presentation. Psychology of Women Quarterly, 38, 46 - 64. http://dx.doi.org/10.1177/0361684313501644

Lopez, S., Oehlert, M., \& Moberly, R. (1996). Selection criteria for American Psychological Association-accredited internship programs: A survey of training directors. Professional Psychology: Research and Practice, 27, 518-520.

Lowe, G. S., Schellenberg, G., \& Shannon, H. S. (2003). Correlates of employees' perceptions of a healthy work environment. American Journal of Health 
Promotion, 17, 390-399. http://doi.org/10.4278/0890-1171-17.6.390

Martinez, L. R., Sawyer, K. B., Thoroughgood, C. N., Ruggs, E. N., \& Smith, N. A. (2017). The importance of being "me": The relation between authentic identity expression and transgender employees' work-related attitudes and experiences. Journal of Applied Psychology, 102, 215-226. http://doi.org/10.1037apl0000168

McCarthy, J. M., \& Goffin, R. D. (2001). Improving the validity of letters of recommendation: An investigation of three standardized reference forms. Military Psychology, 13, 199-222.

Meade, A. W., \& Craig, S. B. (2012). Identifying careless responses in survey data. Psychological Methods, 17, 437-455. http://doi.org/10.1037/a0028085

Mele, C. (2017, June 13). Oregon Court Allows a Person to Choose Neither Sex - The New York Times. Retrieved June 13, 2018, from https://www.nytimes.com/2016/06/14/us/oregon-nonbinary-transgender-sexgender.html

Meyer, I. (1995). Minority stress and mental health in gay men. Journal of Health Sciences and Social Behavior, 36, 38-56. https://doi.org/10.2307/2137286 Meyer, I. H. (2003). Prejudice, social stress, and mental health in lesbian, gay, and bisexual populations: Conceptual issues and research evidence. Psychological Bulletin, 129, 674-697. https://doi.org/10.1037/0033-2909.129.5.674

Meyer, I. H. (2015). Resilience in the study of minority stress and health of sexual and gender minorities. Psychology of Sexual Orientation and Gender Diversity, 2, 209-213. https://doi.org/10.1037/sgd0000132 
Mohr, J. J., \& Rochlen, A. B. (1999). Measuring attitudes regarding bisexuality in lesbian, gay male, and heterosexual populations. Journal of Counseling Psychology, 46, 353-369. http://dx.doi.org/10.1037/0022-0167.46.3.353

National Center for Transgender Equality. Retrieved October 4, 2018, from https://ransequality.org/issues/resources/frequently-asked-questions-abouttransgender-people

Neter, J., Wasserman, W., \& Kutner, M. H. (1989). Applied linear regression models. Chicago, IL: Irwin.

Peer, E., Vosgerau, J., \& Acquisti, A. (2014). Reputation as a sufficient condition for data quality on Amazon Mechanical Turk. Behavioral Research Methods, 46, 1023 1031. http://doi.org/10.3758/s13428-013-0434-y

Peterson, T., Saporta, I., \& Siedel, M. L. (2000). Offering a job: Meritocracy and social networks. American Journal of Sociology, 106, 763-816.

Pfeffer, J., Fong, C. T., Cialdini, R. B., \& Portnoy, R. R. (2006). Overcoming the selfpromotion dilemma: Interpersonal attraction and extra help as a consequence of who sings one's praises. Personality and Social Psychology Bulletin, 32, 13621374. https://doi.org/10.1177/0146167206290337

Preacher, C. J., Rucker, D. D., \& Hayes, A. F. (2007). Addressing moderated mediation hypotheses: Theory, methods, and prescriptions. Multivariate Behavioral Research, 42, 185-227. http://doi.org/10.1080/00273170701341316

Ragins, B. R. (2008). Disclosure disconnects: Antecedents and consequences of disclosing invisible stigmas across life domains. Academy of Management 
Review, 33,194-215. http://doi.org/10.2307/20159383

Ragins, B. R., \& Cornwell, J. M. (2001). Pink triangles: Antecedents and consequences of perceived workplace discrimination against gay and lesbian employees. The Journal of Applied Psychology, 86, 1244-1261.

http://doi.org/10.1037//0021-9010.86.6.1244

Ran, S., Liu, M.,Marchiondo, L. A.,\& Huang, J. L. (2015). Difference in response effort across sample types: Perception or reality? Industrial and Organizational Psychology, 8, 202-208. https://doi.org/10.1017/iop.2015.26

Reed, O. M., Franks, A. S., \& Scherr, K. C. (2015). Are perceptions of transgender individuals affected by mental illness stigma? A moderated mediation analysis of anti-transgender prejudice in hiring recommendations. Psychology of Sexual Orientation and Gender Diversity, 2, 463-469. https://doi.org/10.1037/sgd0000138

Rhoades, L., \& Eisenberger, R. (2002). Perceived organizational support: A review of the literature. Journal of Applied Psychology, 87, 698-714. https://doi.org/10.1037//0021-9010.87.4.698

Richards, C., Bouman, W. P., Seal, L., Barker, M. J., Nieder, T. O., T’Sjoen, G. T. (2016). Non-binary or genderqueer genders. International Review of Psychiatry, 28, 95-102. https://doi.org/10.3109/09540261.2015.1106446

Riggle, R. J., Edmondson, D. R., \& Hansen, J. D. (2009). A meta-analysis of the relationship between perceived organizational support and job outcomes: 20 years 
of research. Journal of Business Research, 62, 1027-1030.

http://doi.org/10.1016/j.jbusres.2008.05.003

Rubin, J. Z., \& Sander, F. E. A. (1988). When should we use agents: Direct vs. representative negotiation. Negotiation Journal, 4, 395-401. https://doi.org/10.1111/j.1571-9979.1988.tb00482.x

Ryland, E. K., \& Rosen, B. (1987). Personnel professionals' reactions to chronological and functional resume formats. Career Development Quarterly, 35, 228-238. http://doi.org/10.1002/j.2161-0045.1987.tb00917.x

Sabat, I. E., Lindsey, A. P., King, E. B., Ahmad, A. S., Membere, A., \& Arena, D. F. (2017). How prior knowledge of LGB identities alters the effects of workplace disclosure. Journal of Vocational Behavior, 103, 56-70.

https://doi.org/10.1016/j.jvb.2017.09.001

Sanders, L. (2018, January 9). Gender X: States embrace non-binary ID choices and Washington and Vermont could be next. Retrieved June 13, 2018, from http://www.newsweek.com/gender-x-new-identity-states-washington-vermont775221

Sawyer, K., \& Thoroughgood, C. (2017). Gender non-conformity and the modern workplace: New frontiers in understanding and promoting gender identity expression at work. Organizational Dynamics, 46, 1-8. https://doi.org/10.1016/j.orgdyn.2017.01.001

Schilt, K. (2006). Just One of the Guys?: How Transmen Make Gender Visible at Work. Gender \& Society, 20, 465-490. https://doi.org/10.1177/0891243206288077 
Schilt, K., \& Connell, C. (2007). Do Workplace Gender Transitions Make Gender Trouble? Gender, Work \& Organization, 14, 596-618. https://doi.org/10.1111/j.1468-0432.2007.00373.x

Schilt, K., \& Wiswall, M. (2008). Before and After: Gender Transitions, Human Capital, and Workplace Experiences. The B.E. Journal of Economic Analysis \& Policy, 8, 1-26. https://doi.org/10.2202/1935-1682.1862

Schilt, K. (2010). Just One of the Guys?: Transgender Men and the Persistence of Gender Inequality. Chicago, IL: University of Chicago Press.

Schlenker, B. R. (1980). Impression management: The self-concept, identity, and interpersonal relations. Monterey, CA: Brooks/Cole.

Sheehan, E. P., McDevitt, T. M., \& Ross, H. C. (1998). Looking for a Job as a Psychology Professor? Factors Affecting Applicant Success. Teaching of Psychology, 25, 8-11. http://doi.org/10.1207/s15328023top2501_3

Swann, W. B., Jr. (1983). Self-verification: Bringing social reality into harmony with the self. In J. Suls \& A. G. Greenwald (Eds.), Social psychological perspectives on the self (Vol. 2, pp. 33-66). Hillsdale, NJ: Erlbaum.

Swann, W. B. (1987). Identity negotiation: Where two roads meet. Journal of Personality and Social Psychology, 53, 1038-1051. http://doi.org/10.1037/00223514.53.6.1038

Tardy, C. H. (1994). Counteracting task-induced stress: Studies of instrumental and emotional support in problem-solving contexts. In B. R. Burleson, T. L. Albrecht 
\& I. G. Sarason (eds), Communication of Social Support: Messages, Interactions, Relationships, and Community. Thousand Oaks, CA: Sage, pp. 71-87.

Thomas, L. T., \& Ganster, D. C. (1995). Impact of family-supportive work variables on work-family conflict and strain: A control perspective. Journal of Applied Psychology, 80, 6-15. http://doi.org/10.1037/0021-9010.80.1.6

Thoroughgood, C. N., Sawyer, K. B., \& Webster, J. R. (2017). What lies beneath: How paranoid cognition explains the relations between transgender employees' perceptions of discrimination at work and their job attitudes and wellbeing. Journal of Vocational Behavior. https://doi.org/10.1016/j.jvb.2017.07.009

Tilcsik, A. (2011). Pride and prejudice: Employment discrimination against openly gay men in the United States. American Journal of Sociology, 117, 586-626. https://doi.org/10.1086/661653

Vaux, A. (1988). Social support: Theory, research and intervention. New York, NY: Praeger.

Viswesvaran, C., Sanchez, J. I., \& Fisher, J. (1999). The role of social support in the process of work stress: A meta-analysis. Journal of Vocational Behavior, 54, 314-334. http://doi.org/10.1006/jvbe.1998.1661

Walter, S. L., Seibert, S. E., Goering, D., \& O’Boyle, E. H. (2018). A Tale of Two Sample Sources: Do Results from Online Panel Data and Conventional Data Converge? Journal of Business and Psychology. Advance online publication. https://doi.org/10.1007/s10869-018-9552-y 
Wayment, H. A., \& Peplau, L. A. (1995). Social support and well-being among lesbian and heterosexual women: A structural modeling approach. Personality and Social Psychology Bulletin, 21, 1189-1199. https://doi.org/10.1177/01461672952111007

Wayne, S. J., Shore, L. M., \& Liden, R. C. (1997). Perceived organizational support and leader-member exchange: A social exchange perspective. Academy of Management Journal, 40, 82-111. http://doi.org/10.2307/257021

Webb, A., Matsuno, E., Budge, S., Krishnan, M., \& Balsam, K. (2015). Non-Binary Gender Identities Fact Sheet. Washington, D.C.: American Psychological Association.

Weichselbaumer, D. (2003). Sexual orientation discrimination in hiring. Labour Economics, 10, 629-642. https://doi.org/10.1016/S0927-5371(03)00074-5

West, C., \& Zimmerman, D. H. (1987). Doing Gender. Gender and Society, 1, 125-151. https://doi.org/10.1177/0891243287001002002

Witt, L. A., \& Carlson, D. S. (2006). The work-family interface and job performance: Moderating effects of conscientiousness and perceived organizational support. Journal of Occupational Health Psychology, 11, 343-357. https://doi.org/10.1037/1076-8998.11.4.343

Wortman, C. B., \& Dunkel-Schetter, C. (1987). Conceptual and methodological issues in the study of social support. In A. Baum \& J. E. Singer (Eds.), Handbook of psychology and health (Vol. 5, p. 63-108). Hillsdale, NJ: Erlbaum. 
Waung, M., McAuslan, P., DiMambro, J. M., \& Mięgoć, N. (2017). Impression management use in resumes and cover letters. Journal of Business and Psychology, 32, 727-746. https://doi.org/10.1007/s10869-016-9470-9 


\section{Appendix A}

\section{Measures}

Overview of Measures by Source and Data Collection Timing

\begin{tabular}{|l|l|l|}
\hline Measure & \# Items & Data Collection Timing \\
\hline Perceived Hireability & 14 & Survey 1 \\
\hline $\begin{array}{l}\text { Perceived Ability to Provide } \\
\text { Social Support }\end{array}$ & 10 & Survey 1 \\
\hline $\begin{array}{l}\text { Instability of Non-Binary } \\
\text { Gender Identity }\end{array}$ & 8 & Survey 2 \\
\hline Demographics & 9 & Survey 2 \\
\hline
\end{tabular}


Measures

Perceived Hireability (Adapted from King, Mendoza, Madera, Hebl, \& Knight, 2006)

Please rate the extent to which you agree with each of the following statements regarding the applicant.

1=Agree not at all, 2=Agree not very much, 3=Somewhat Agree, 4=Moderately Agree, 5=Agree, $6=$ Strongly agree, $7=$ Completely agree

1. This individual seems intelligent.

2. This individual seems creative.

3. This individual seems friendly.

4. This individual seems responsible.

5. This individual seems competitive.

6. This individual seems motivated.

7. This individual seems likable.

8. This individual seems ambitious.

9. I would want to work with this individual.

10. I would offer this individual an interview.

11. I would hire this individual.

12. I would likely promote this individual within the first year.

13. I would likely increase the salary of this individual within the first year.

14. I would likely give this person a bonus in the first year.

Please share any other reactions to this applicant. We just want your honest opinion [open-ended].

\section{Perceived Ability to Provide Social Support (adapted from House \& Wells' Social Support Scale, 1978)}

Concerning work-related problems, to what degree do you feel able to support the prospective applicant? Please indicate your level of agreement with the following statements.

$1=$ Agree not at all, $2=$ Agree not very much, $3=$ Somewhat Agree, $4=$ Moderately Agree, $5=$ Agree, $6=$ Strongly agree, $7=$ Completely agree

1. I would be able to listen to this person's work-related problems.

2. I would be able to show concern towards this person's job-related problems.

3. I would be able to give this person aid in dealing with work-related problems.

4. I would be able to give this person tangible assistance to deal with their work-related stress. 
5. I would be able to give this person sound advice about problems encountered on the job.

6. I would be able to give this person useful suggestions in order to get through difficult times.

7. I would be able to help this person manage conflicts with coworkers.

8. I would be able to help this person fit in at work.

9. I would be able to help this person make meaningful connections at work.

10. I would be able to help this person if they were to experience issues with discrimination or harassment on the job.

\section{Manipulation Check}

What was the gender of the applicant?

Female

_ Male

_ Non-Binary

Did not specify

_ I don't remember

Other

What personal information was revealed? Check all that apply.

_ The applicant has a "non-binary" gender.

_ The applicant volunteered at a queer center.

_ The applicant has cancer.

_ There was no personal information revealed.

Instability of Gender Non-Binary Identity (Adapted from Attitudes Regarding Bisexuality scale; Mohr and Rochlen, 1999)

Please rate the extent to which you agree with each of the following statements. Please remember that there are no right or wrong answers. We are just interested in your honest opinions and reactions.

Gender non-binary refers to people who do not identify as exclusively male or female.

1=Agree not at all, 2=Agree not very much, 3=Somewhat Agree, 4=Moderately Agree, $5=$ Agree, $6=$ Strongly agree, $7=$ Completely agree

1. People who call themselves gender non-binary can't decide what gender they want to be. 
2. Most people who claim to be gender non-binary are just experimenting with their gender.

3. Gender non-binary is usually just a phase, not a real gender identity.

4. Unlike male and female, gender non-binary is not a real gender identity.

5. The only true gender identities are male and female.

\section{Demographics}

Please provide the following information about yourself.

What is your age?

What is your gender?

Female

Male

Non-Binary

Genderqueer

MTF Transgender

FTM Transgender

Agender

Other

What race/ethnicity do you identity with?

White/Non-Hispanic

African American/Black

Hispanic/Latino

Asian

Native American/Alaskan Native

Native Hawaiian/Pacific Islander

Indian/South Asian

Middle Eastern

_ Biracial/Multiracial

Other

What sexual orientation do you most closely identify with?

Straight/Heterosexual

_ Gay/Lesbian

Bisexual

Asexual

Queer

Polyamorous

Other

Do you identify as a member of the LGBTQ community? 
Yes
No
No, but I'm an ally

Do you have any close friends or family members who are transgender or non-binary?

Yes

No

I'm not sure

Highest level of education received:

Some High School

High school or GED

Some college

__ Vocational degree

Bachelor's Degree

Master's Degree

PhD/MD or other terminal degree

What is your current employment status?

_ Student

Unemployed

_ Part-Time Employed

_ Full-Time Employed

How much managerial experience do you have?

None

1-2 years

3-5 years

6-10 years

More than 10 years

Do you currently supervise employees?

Y Yes

No

Do you have hiring experience such that you have hired other people for jobs before?

Yes

No 


\section{Appendix B}

\section{Pilot Study}

I conducted a preliminary study with two aims. First, I tested whether the gender identity of the applicant was salient to participants in the resume, cover letter, and letters of recommendation in the non-binary disclosure conditions. Second, I pre-tested various gender-neutral names for the applicant. In line with the recommendation of Highhouse (2009), the goal was to extract two exemplars, which would help ensure that any differences found were not a factor of idiosyncratic features related to any one name.

\section{Method}

\section{Participants}

I recruited participants $(n=794)$ from Amazon's MTurk to participate in the pilot study in exchange for \$.10. I removed 249 cases associated with non-US IP addresses, resulting in a final sample of 545. A majority of participants were White $(71 \%, n=385)$, female $(55 \%, n=299)$, and heterosexual $(84.6 \%, n=457)$.

\section{Procedure}

All participants were told that a marketing services company was testing a new crowd-sourced method of hiring and were looking for feedback from web users on candidates for a specific job opening. They were then instructed to read a job description for an entry-level Marketing Coordinator position, and then review application materials and provide ratings for one job applicant. All participants viewed the same job description for an entry-level marketing position and instructions before reviewing the application materials of one applicant. Application materials were presented in the same 
way they would ultimately be presented in the actual study, with all materials presented at the same time so that the participant could view them together. Participants were allowed to progress in the survey only after three minutes, upon which they were asked to answer questions about the applicant. Two multiple choice items were used to assess the salience of the disclosure and perceived gender identity of the applicant: "What was the gender of the applicant" and "What personal information was revealed?"

\section{Materials}

I developed a job description for the fictional job opening as well as all application materials to be used in this study, including resumes, cover letters, and letters of recommendation (see Appendix C for all materials). Six names (Alex, Alyx, Scout, Skylar, Phoenix, and Quinn) were tested in application materials across all four conditions (self-disclosure: yes versus no $\mathrm{X}$ other-disclosure: yes versus no), for a total of 24 conditions. The first names were chosen from lists of gender-neutral names, including lists of name ideas for non-binary people who are considering name changes. To examine the validity of these resumes, they were reviewed by two managers who had previous experience reviewing entry-level marketing candidate resumes.

Job Description. To create the job description, I reviewed actual advertisements for entry-level marketing positions at for-profit companies requiring a bachelor's degree and one to two years of work experience. All participants viewed the same job description.

Resumes. I included two versions of the resume: one in which the applicant discloses a non-binary gender identity via the placement of gender neutral pronouns (i.e., 
"they/them/their") in the resume header and the mention of community service as a volunteer at a queer center where they facilitated non-binary group meetings, and one in which the applicant does not list gender pronouns and volunteers at an environmental organization. The resumes were otherwise identical.

Cover Letters. Cover letters were identical across conditions with the exception of one sentence in which the person discloses some personal information. In the selfdisclosure condition, the applicant stated, "As a person who identifies as a gender other than the one assigned to me at birth (I am non-binary), I have had to overcome a lot of personal challenges in my life. Those experiences of becoming and expressing my true self have made me a highly resilient, self-aware, and self-confident person and I know I can tackle any challenge that comes my way." In the non-disclosure condition, it stated, "I have had to overcome a lot of personal challenges in my life. Those experiences have made me a highly resilient, self-aware and self-confident person and I know I can tackle any challenge that comes my way."

Letter of recommendation. Recommendation letters were identical across conditions with the exception of one sentence. In the disclosure condition, the sentence said, “Alyx (Skylar, Alex, Quinn, Scout, or Phoenix) has had some unique personal experiences and has faced a lot of obstacles. They came out as gender non-binary while working at our organization. Alyx (Skylar, Alex, Quinn, Scout, or Phoenix) was able to manage their coming out process very well. Their confidence and poise helped ensure a smooth transition for everyone and speaks a great deal to their ability to communicate thoughtfully and professionally in challenging situations." In the non-disclosure 
condition, it said, "Alyx (Skylar, Alex, Quinn, Scout, or Phoenix) has had some unique personal experiences and faced a lot of obstacles. Alyx (Skylar, Alex, Quinn, Scout, or Phoenix) had some personal challenges come up while working at our organization. Alyx (Skylar, Alex, Quinn, Scout, or Phoenix) was able to manage them very well. Alyx's (Skylar's, Alex's, Quinn's, Scout's, or Phoenix's) confidence and poise in managing the situation helped ensure better outcomes for everyone and speaks a great deal to their ability to communicate thoughtfully and professionally in challenging situations."

\section{Measures}

The pilot study measures included two items. The first item asked, "What was the applicant's gender," with response options of "male," "female," "non-binary," "I don't remember," "didn't specify," and "other." The correct answer for the disclosure conditions was "non-binary," but "other" was also considered a correct answer based on the assumption that participants who answered in such a way recalled that the applicant disclosed a gender other than male or female. All other answers were scored as failures. The second item asked, "What did the applicant disclose," with response options of "The applicant has a 'non-binary' gender," "The applicant volunteered at a queer center," "The applicant volunteered at an environmental organization," "The applicant has cancer," and "No personal information was disclosed." Applicants could select more than one answer. Although the applicant in the disclosure conditions volunteered at a queer center, the only correct answer accepted for this item was "The applicant has a "non-binary' gender." 


\section{Results}

I analyzed frequencies of correct answers for both items across all six names and four disclosure conditions. Results indicated that the names Alyx and Skylar were the most gender neutral and had the highest manipulation check success rates. Participants in disclosure conditions correctly identified Skylar as non-binary in disclosure conditions $67 \%$ of the time (full disclosure: $76 \%$; self only: $80 \%$; other only: $43 \%$ ), the highest manipulation check passing rate compared to all other names (Alyx: 61\%, Scout: 61\%, Quinn: 63\%, Phoenix: 62\%, Alex: 65\%). Participants correctly identified Alyx as nonbinary $61 \%$ of the time (full disclosure: $75 \%$; self only: $59 \%$; other only: $50 \%$ ).

Additionally, $71 \%$ of participants correctly answered the second item ("What did the applicant disclose?") for Skylar disclosure conditions. Although there was variability in responses to the other names, the percentages of people correctly identifying the gender identity of applicants was highest for Alyx and Skylar. Although Alyx's manipulation check passing rate was lower than some other names for both of these items (61\% and $62 \%$ respectively), the name was perceived as the most gender neutral among all the names. Participants in the control (no disclosure) condition were equally likely to assume that Alyx was either male (7 out of 20 participants) or female (8 out of 20 participants), with five participants assuming the applicant's gender was "other" or "non-binary," indicating that Alyx is relatively gender neutral. Similarly, participants in the Skylar control (no disclosure) condition were equally likely to assume the applicant was either male (11 out of 26 ) or female (10 out of 26$)$, with five participants assuming the applicants was an "other" or "non-binary" gender. Participants in the control (no 
disclosure) conditions for the other four names were more likely to perceive the applicants as primarily male or female.

Based on this data, I determined Skylar and Alyx both satisfactorily passed manipulation checks and were the most gender-neutral names for the study. I therefore utilized the names Skylar Johnson and Alyx Johnson in resumes, cover letters, and letters of recommendation in the actual study. 


\section{Appendix C}

Study Materials

\section{Table 3 - Instructions \& Stimuli}

\section{$\underline{\text { Instructions }}$}

LifeOpps is a marketing services company based in the Pacific Northwest. The firm is hiring for a new Marketing Coordinator position. To accomplish this, they are testing a new crowd-sourced method of hiring so are seeking input from web users, with help from researchers at Portland State University. On the next screen, you will review the job description and then a resume of an applicant and rate that applicant on hireability.

\section{Stimuli}

\section{$\underline{\text { Job Description }}$}

\section{Marketing Coordinator}

\section{Overview}

LifeOpps is looking for a Marketing Coordinator for its growing office in downtown Portland. This person will support the marketing team in developing and implementing marketing campaigns and projects, performing research, building reports, updating content, and serving as central coordinator for strategic projects.

\section{Responsibilities}

- Assist in developing marketing and sales content, including data sheets and presentations.

- Provide campaign, reporting and demand generation support for large-scale campaigns.

- Aid in customer market research projects

- Support sales team members with regular updates, materials and training as needed.

\section{Qualifications}

- 2+ years' experience in any combination of sales and/or marketing.

- Demonstrated experience in creation of marketing and sales content, campaign execution, and tool production.

- Experience working in a distributed and fast-paced work environment.

- Ability to work in a collaborative, cross-team capacity.

- Exceptional communication skills to collaborate across the marketing team and other stakeholders. 


\section{$\underline{\text { Resumes }}$}

\section{Alyx Johnson (Skylar Johnson) (They/Them/Their)}

PROFESSIONAL EXPERIENCE:

Big Idea Group Portland, OR

August $2016-$

Present

Marketing Communications Assistant

* Worked closely with the Marketing Coordinator and Marketing Manager to produce materials for the company blog, intranet, and social media channels sisep]

* Managed the company's social media channel output (LinkedIn, Twitter, Facebook),

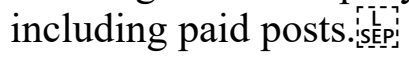

* Created weekly analytics reports for multi-platform marketing and social media campaigns išpin

Creative Anvil Portland, OR

June 2014 -

August 2016

Marketing Intern

* Assisted in the creation of marketing and advertising campaigns for over 15 clientsisêp

* Performed analyses of marketing and sales data, including analyses of competitor marketing materialsis'

* Prepared presentations for sales executives and performed online researchiseppi

\section{EDUCATION:}

Portland State University, Bachelor of Science in Marketing, Portland, OR

May 2016

Lake Oswego High School

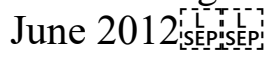

\section{COMMUNITY SERVICE:}

SOLVE Portland, OR

July 2017-

Present

Volunteer

* Facilitated monthly cleanup events of the Willamette River

( $Q$ Center Portland, OR

July 2017-

Present

Volunteer

* Facilitated weekly meetings for Gender Queery, a discussion group for people who identify as genderqueer or non-binary) 
SKILLS:

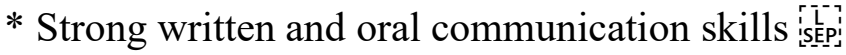

* Able to work in fast-paced, results-oriented environmentsișép

* Proven track record in managing social media for small, medium and large organizationsis

* Social media management and analytics (Twitter, Facebook, Instagram, LinkedIn), with software including Hootsuite and Bufferisep?

* Google Docs and Microsoft Office Suites

\section{Cover Letters}

Dear Hiring Manager,

I am excited to submit my application for the open Marketing Coordinator position with LifeOpps. I believe that my education and employment experiences make me an ideal candidate for the position.

After graduating from Portland State University with a degree in marketing and completing an internship at Creative Anvil, I accepted a position at the Big Idea Group as Marketing Communications Assistant. I am responsible for managing the company blog, intranet, and social media channelsisÉp. and creating weekly analytics reports for multiplatform marketing and social media campaignsis.

I have had to overcome a lot of personal challenges in my life. Those experiences have made me a highly resilient, self-aware and self-confident person and I know I can tackle any challenge that comes my way. (As a person who identifies as a gender other than the one assigned to me at birth (I am non-binary), I have had to overcome a lot of personal challenges in my life. Those experiences of becoming and expressing my true self have made me a highly resilient, self-aware, and self-confident person and I know I can tackle any challenge that comes my way.)

I believe that my experiences in marketing and my interpersonal skills make me a prime candidate for the Marketing Coordinator position. I am a diligent worker, and passionate about my work. I believe I would be a valuable asset to LifeOpps and look forward to the chance to discuss this opportunity further.

Thank you very much for your time in considering my application.

Best regards,

Alyx Johnson (Skylar Johnson)

(They/Them) 


\section{Letter of Recommendation}

Human Resources

LifeOpps

101 Broadway

Portland, OR 97201

Dear Hiring Manager,

Alyx Johnson (Skylar Johnson) reported to me at Creative Anvil marketing agency from June 2014 to August 2016. Alyx (Skylar) was a marketing intern who worked in most areas of our company's marketing department. Alyx (Skylar) particularly contributed to key client campaigns through copywriting, the creation of marketing proposals, and market research.

Alyx (Skylar) has had some unique personal experiences and faced a lot of obstacles. Alyx (Skylar) had some personal challenges come up while working at our organization. Alex was able to manage them very well. Alyx's (Skylar) confidence and poise in managing the situation helped ensure better outcomes for everyone and speaks a great deal to their ability to communicate thoughtfully and professionally in challenging situations. (Alyx (Skylar) has had some unique personal experiences and has faced a lot of obstacles. They came out as gender non-binary while working at our organization. Alyx (Skylar) was able to manage their coming out process very well. Their confidence and poise helped ensure a smooth transition for everyone and speaks a great deal to their ability to communicate thoughtfully and professionally in challenging situations.)

I recommend Alyx (Skylar) for any position that will draw upon Alyx's (Skylar) (their) skills and proven record of contribution to marketing. Alyx (Skylar) was (They were) a remarkable colleague and contributor. Feel free to call me if you need additional information.

Regards,

Michael R. Cox

Marketing Manager

Creative Anvil 